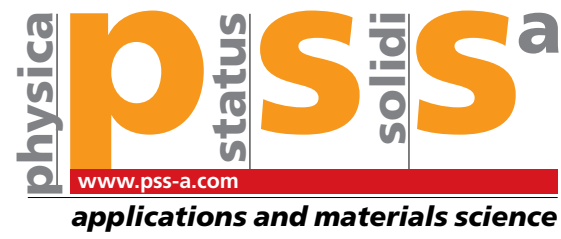

\section{From colossal magnetoresistance to solar cells: An overview on 66 years of research into perovskites}

\author{
Patrick Wagner $^{*, 1}$, Gideon Wackers' ${ }^{1}$, Ilaria Cardinaletti ${ }^{2}$, Jean Manca ${ }^{3}$, and Johan Vanacken ${ }^{4}$ \\ ${ }^{1}$ Department of Physics and Astronomy, Soft-Matter Physics and Biophysics Section (ZMB), Celestijnenlaan 200 D, 3001 Leuven, \\ Belgium \\ ${ }^{2}$ Hasselt University, Institute for Materials Research (IMO-IMOMEC), Wetenschapspark 1, 3590 Diepenbeek, Belgium \\ ${ }^{3}$ Hasselt University, X-LAB, Agoralaan, Gebouw D, 3590 Diepenbeek, Belgium \\ ${ }^{4}$ KU Leuven, Department of Physics and Astronomy, Laboratory of Solid-State Physics and Magnetism (LVSM), Celestijnenlaan 200 D, \\ 3001 Leuven, Belgium
}

Received 20 June 2017, revised 13 July 2017, accepted 13 July 2017

Published online 4 August 2017

Keywords catalysis, magnetoresistance, perovskites, photovoltaics, superconductivity, transition metals

*Corresponding author: e-mail patrickhermann.wagner@kuleuven.be, Phone: +32 1632 21 79, Fax: +32 16327810

Perovskites are a huge family of compounds to which the natural titanium mineral $\mathrm{CaTiO}_{3}$ is the common ancestor. The cubic structure looks apparently simple, but the variety of metal ions and mixtures thereof that fit into a perovskite lattice is tremendous. Even in the case that the ionic radii do not allow for a perfect cubic ordering, there are various superstructures and orbital-ordering effects to cope elegantly with distortions. The compositional and structural flexibility offers a large toolbox to design and synthesize perovskites with tailored properties searched for by physicists, chemists, materials scientists and device engineers. These materials are equally of interest for fundamental studies and for applied research while both viewpoints cross-fertilize each other regularly. Our overview starts with the discovery of ferromagnetism in manganites in 1950 and ranges until 2016: Today, halide perovskites are fully in focus for their potential in photovoltaic applications. This is certainly not an endpoint, but another milestone in a long series of often-unexpected discoveries on an 'evergreen material'.

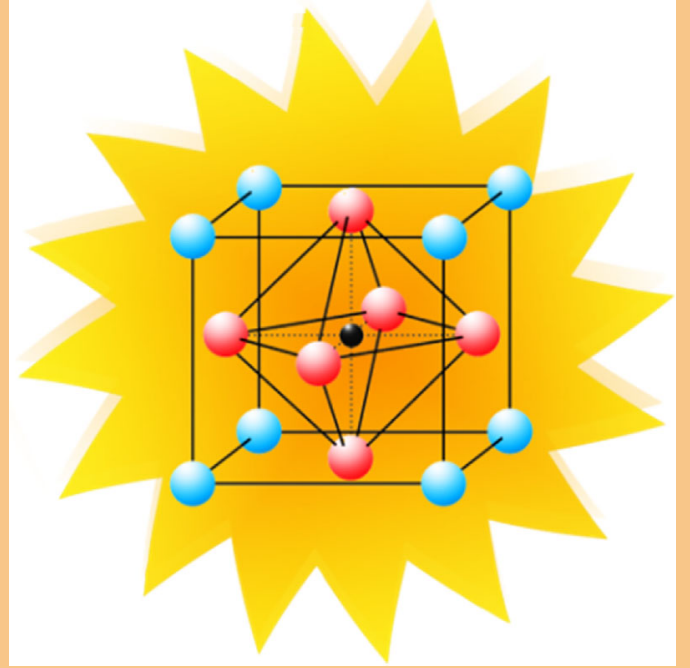

Ball-and-stick model of the ideal cubic perovskite structure. The cation at the central position or 'B site' (small black dot) defines the group name (e.g., titanates) and plays a key role for the physical properties of the material.
1 Introduction The term 'perovskites' describes today a wide family of natural and synthetic oxides with a cubic or orthorhombic structure and the general formula $\mathrm{ABO}_{3}$ with $\mathrm{A}$ and $\mathrm{B}$ being metal ions. They gain their name from the mineral calcium titanate, $\mathrm{CaTiO}_{3}$, which was discovered 1839 by G. Rose in the Ural Mountains and later named after the mineralogist L.A. Perovski. Closely related to this mineral are strontium titanate, $\mathrm{SrTiO}_{3}$, discovered as the sparse mineral 'tausonite' just in 1982 , and $\mathrm{BaTiO}_{3}$, which hardly occurs in nature in pure 
form. Similar to these titanates, there are also silicate perovskites with the general formula $(\mathrm{Mg}, \mathrm{Fe}) \mathrm{SiO}_{3}$. Ironmagnesium silicates are abundantly present in the Earth's lower mantle, where they are stabilized by the high pressure-high temperature conditions. Pure $\mathrm{MgSiO}_{3}$ was so far only found on the Earth's surface as inclusions in the Tenham meteorite and named 'bridgmanite' in 2014, in honour of P.W. Bridgman who was awarded the Nobel Prize in Physics in 1946 [1]. Besides silicates and titanates, there is a wide variety of oxides termed after the $B$ site ion such as ferrites, cobaltates, chromates, tantalates, niobates, cuprates and manganites. The A sites (corner positions) and $\mathrm{B}$ sites (central position) are illustrated in Fig. 1a, rendering exemplarily the structure of $\mathrm{BaTiO}_{3}$. Practically all metal ions from Mendeleev's table can occur in natural- or synthetic perovskites, provided the ionic radii of A and B fulfill certain stability criteria discussed in Section 2 and that their summed-up chemical valence is +6 . Both 'guidelines' are not really strict since a non-ideal ratio of radii can often be compensated by slight deviations from the cubic structure and vacancies on the $\mathrm{O}^{2-}$ sites are possible as well.

This considerable flexibility gives rise to a plethora of effects and physical properties, which can often be tuned within a wide parameter range: The $A$ sites can for example, be occupied by mixtures of di- and trivalent cations provided they have a similar diameter. Using B-site ions that occur in different valence states (such as iron, copper and manganese) results in mixed-valence perovskites, which show electrical conductivity. Rare earth- or transition metal ions at the $\mathrm{B}$ position often go along with magnetic ordering phenomena. A few types of $\mathrm{B}$ ions $\left(\mathrm{Cu}^{2+}, \mathrm{Mn}^{3+}\right)$ are JahnTeller active, resulting in spontaneous local or collective lattice distortions, affecting in turn the electronic conduction and the magnetic structure.

Our overview starts with the discovery of ferromagnetic ordering in $\left(\mathrm{La}_{1-x} \mathrm{Sr}_{x}\right) \mathrm{MnO}_{3}$ mixed crystals by G. H. Jonker and J. H. Van Santen in 1950 [2]. Hence, we take 1950 as the starting year of research into perovskites from the viewpoint

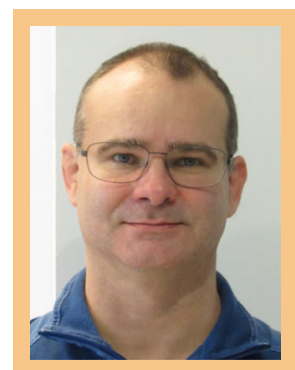

Patrick Wagner received his Ph.D. in Physics in 1994 at TU Darmstadt and was postdoctoral researcher at $\mathrm{KU}$ Leuven from 1995 till 2001. In 2001, he was appointed as a professor for biophysics at Hasselt University and he returned in 2014 as full professor back to KU Leuven. His main research field is the development of bioanalytical sensors for diagnostic and environmental applications with a special focus on synthetic receptors and thermal detection principles. He has authored or coauthored 250 publications and received several scientific distinctions. Since 2016, P. Wagner is editor-in-chief of the new Elsevier journal Physics-in-Medicine.
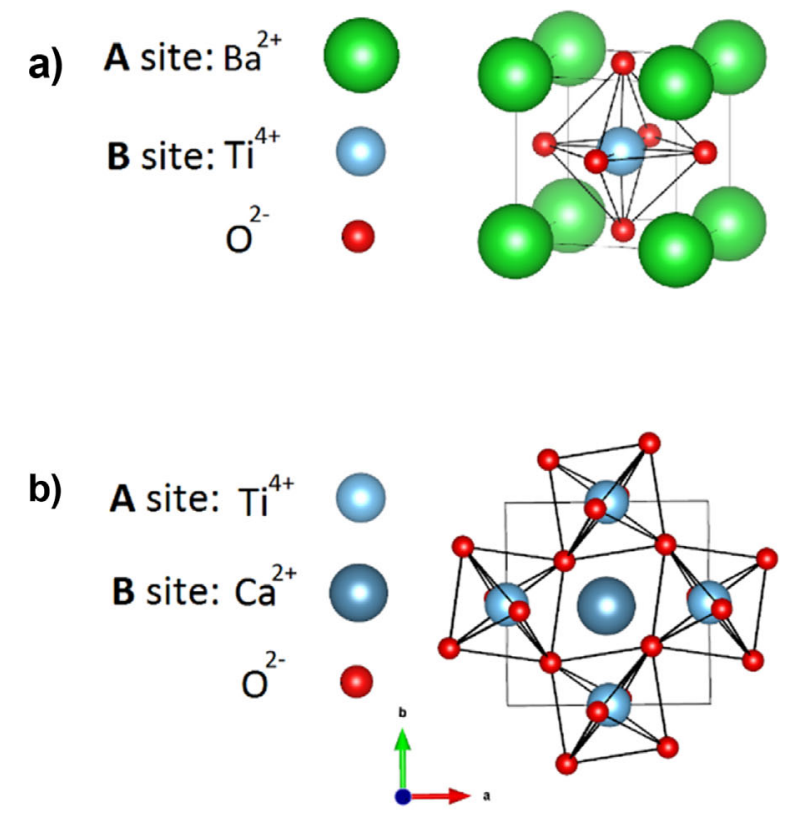

c)

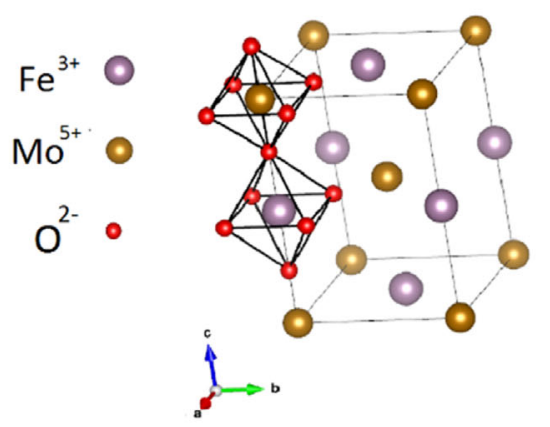

d)

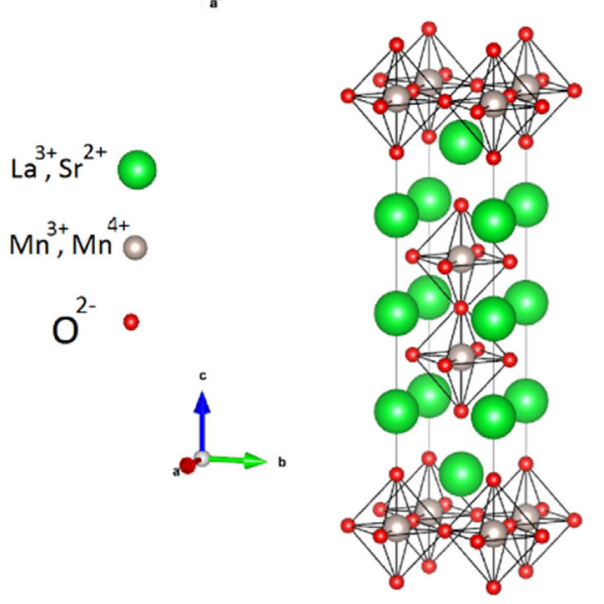

Figure 1 a) shows the ideal cubic perovskite structure found in BaTiO3 $(t=0.96$, space group $\mathrm{Pm} 3 \mathrm{~m}), \mathrm{b})$ orthorhomically distorted superstructure of $\mathrm{CaTiO}_{3}(t=0.83)$ seen as projection along the $\mathrm{c}$ axis with tilt and rotation of the $\mathrm{TiO}_{6}$ octahedra, and c) the cubic double-perovskite structure found in $\mathrm{Sr}_{2} \mathrm{FeMoO}_{6}$ [14]. For clarity, only the rocksalt-type sublattice of $\mathrm{Fe} 3+$ and Mo6+ is shown with two $\mathrm{O}^{-}$octahedra. Panel d) illustrates the unit cell of the bilayer perovskite $\mathrm{LaSr}_{2} \mathrm{Mn}_{2} \mathrm{O}_{7}$ with $\mathrm{Mn} 3+$ and Mn4+ in equal numbers; see Ref. [15]. 
of functional properties, not forgetting about earlier crystallographic work by V. Goldschmidt and H. Megaw $[3,4]$. Also in 1950, Jonker and Van Santen noticed that the conductivity of these perovskites changes from semiconductor-like above the Curie temperature $T_{C}$ to metallic-like below $T_{\mathrm{C}} \approx 270 \mathrm{~K}$ [5]. Negative magnetoresistance with $\Delta R /$ $R_{0} \approx-8 \%$ slightly below $T_{\mathrm{C}}$ was observed by J. Volger in 1954 in a field of 3000 Oe $(300 \mathrm{mT})$ [6]. The relative resistance drop was not spectacular; however, the fact of a resistance decrease instead of the conventional, weakly positive magnetoresistance was remarkable. In the same period, also the first report by G. Parravano was published on the catalytic activity of $\mathrm{La}_{0.65} \mathrm{Sr}_{0.35} \mathrm{MnO}_{3}$ for the oxidation of carbon monoxide [7].

In 1993, manganites made a vibrant revival when $\mathrm{R}$. von Helmolt found resistance drops by $60 \%$ in epitaxial thin films at room temperature in a six Tesla field: The term colossal negative magnetoresistance (CMR) was born [8]. A few years earlier, in 1986, a ground-breaking discovery had taken place in the field of electrically conducting oxides: J. G. Bednorz and K. A. Müller reported high-temperature superconductivity (HTSC) in perovskite-related cuprates [9]. Both received the Nobel Prize in Physics in 1987 'for their important break-through in the discovery of superconductivity in ceramic materials and a worldwide wave of topical research programs was launched. Today, 30 years later, cuprates are somewhat out of focus but oxide electronics in the broadest sense became a well-established field with plenty of facets. Also here, the first studies date a long way back and, as an example, the dielectric properties of para- and ferroelectric titanates were systematically mapped by G. Rupprecht and R. O. Bell in 1964, laying the foundations for multiferroic materials [10].

Besides of perovskites belonging to the oxides, there is also increasing attention for halide-based perovskites. First publications on this topic date back to 1985 and earlier [11]. In the sum formula $\mathrm{ABX}_{3}$ the $X$ stands for $\mathrm{F}, \mathrm{Cl}, \mathrm{Br}$, or I while $A$ and $B$ are mono- and divalent cations, respectively. Although this review article addresses mainly oxide-type perovskites, we will discuss halide perovskites in Section 8 in the context of emerging photovoltaic applications. Since the first publication on perovskite-sensitized solar cells with high efficiency by M. Grätzel and co-workers in late 2012, this is a more than flourishing field [12, 13]. Already for the year 2015, Web-of-Science documents more than 1500 articles under the keyword 'perovskite solar cell'. This is an overwhelming boom, which can only be compared to the worldwide research efforts launched after the discovery of high-temperature superconductivity in cuprates.

This review article will cover the years from 1950 until 2016 and we will not only focus on the 'highlights' mentioned above, but also on a few niche applications in which perovskites play a decisive role. It would be impossible to provide a complete overview on all existing topical literature and therefore we limit ourselves to selected, but representative results. Wherever possible, the reader will be referred to review articles and books in which selected sub-topics of perovskite research are discussed in full detail. Also, this feature article seeks to present the topic not only from the viewpoint of solid-state physics but tries to motivate the interest in these special compounds also from the perspective of chemistry, materials science and device engineering.

\section{The perovskite structure and its derivatives}

2.1 Simple-cubic perovskites and the tolerance

factor The composition of perovskites is flexible regarding the cations $\mathrm{A}$ and $\mathrm{B}$ as long as charge neutrality of the unit cell is given. However, it depends on the ionic radii $r$ of $A$ and $B$ whether a perfectly cubic structure will be formed or a distorted structure with lower, usually tetragonal or orthorhombic symmetry. When looking at the perfectly cubic structure in Fig. 1a), the height is given by $r_{\mathrm{A}}+r_{\mathrm{O}}$ while the side-diagonal length is defined by $r_{\mathrm{B}}+r_{\mathrm{O}}$. In a perfect cube, the lattice constant and side diagonals are in the ratio $1 / \sqrt{ } 2$. Based on this geometric consideration, V. M. Goldschmitt defined in 1926 the tolerance factor $t$, given by Eq. (1) [3]:

$$
t=\frac{r_{A}+r_{O}}{\sqrt{2}\left(r_{B}+r_{O}\right)}
$$

Perovskites with $t \approx 1$ are cubic, for $t<0.9$ distortions are expected, and stable compounds with $t>1.0$ are not identified so far, neither natural nor synthetic. When looking at the ionic radii of $\mathrm{Ca}^{2+}(97 \mathrm{pm}), \mathrm{Ba}^{2+}(135 \mathrm{pm})$, $\mathrm{Ti}^{4+}(61 \mathrm{pm})$ and $\mathrm{O}^{2-}(145 \mathrm{pm})$, we obtain $t=0.96$ for $\mathrm{BaTiO}_{3}$ (cubic above $120^{\circ} \mathrm{C}, a=3.996 \AA$ ) and $t=0.83$ in case of $\mathrm{CaTiO}_{3}$ (orthorhombically distorted). A low $t$ value means that the $\mathrm{BO}_{3}$ octahedra are too large to fit into the cube defined by the $\mathrm{A}$ ions at the corner positions. This is compensated by an alternating tilt- and rotation pattern of these octahedra, resulting in the superstructure of $\mathrm{CaTiO}_{3}$ shown in Fig. 1b. The orthorhombic crystallographic unit cell $(a=5.387 \AA$ A $b=5.439 \AA, c=7.646 \AA)$ has four times the volume of the chemical unit cell [16]. In approximation, we can write $a \approx b \approx \sqrt{ } 2 a^{\prime}$ and $c \approx 2 a^{\prime}$, with $a^{\prime}$ denoting the cubic unit cell. The concept of the tolerance factor, defined so far only for perovskites, was recently extended to the ionic filling fraction IFF that is applicable to arbitrary crystalline structures [17].

2.2 Jahn-Teller deformations and orbital ordering In case of specific B-site ions, with $\mathrm{Cu}^{2+}$, $\mathrm{Ni}^{3+}$ and $\mathrm{Mn}^{3+}$ as best-known examples, the $\mathrm{BO}_{6}$ octahedra can show a spontaneous deformation to an elongated or compressed form as shown in Fig. 2. This is a result of the Jahn-Teller (JT) theorem, stating that the ground-state energy of a system, be it a molecule or a crystalline unit cell, can be lowered upon a structural deformation which lifts the energetic degeneracy of electron orbitals [18]. In case of $\mathrm{Mn}^{3+}$, there are four electrons in the $3 \mathrm{~d}$ orbitals. Three of them occupy the energetically equivalent $\mathrm{xy}-\mathrm{xz}-$ and $\mathrm{yz}$ orbitals $\left(t_{2 g}\right.$ states) while the fourth electron, at the 


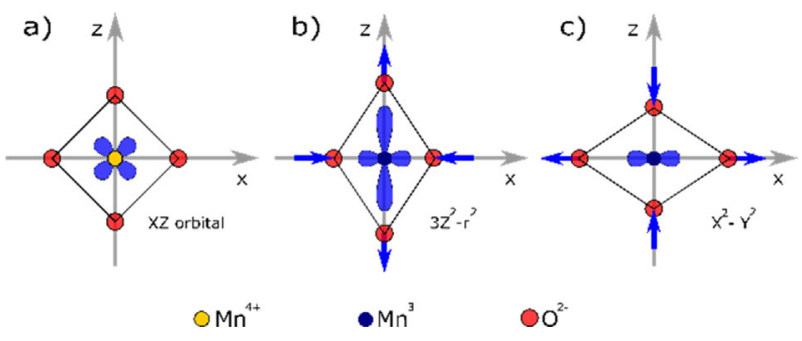

Figure 2 a) Projection of a non-distorted $\mathrm{Mn}^{4+} \mathrm{O}^{2-}$ octahedron in the $x z$ plane; the $3 \mathrm{~d}$ states $\mathrm{xy}, \mathrm{xz}$ and $\mathrm{yz}$ are occupied. b) Stretching of a $\mathrm{Mn}^{3+} \mathrm{O}_{6}{ }^{2-}$ octahedron with a deformation parameter $\delta$ favours occupation of the $3 d\left(3 z^{2}-r^{2}\right)$ orbital due to the Jahn-Teller effect. c) Compression along $\mathrm{z}$ and expansion in the xy plane favours the $3 d\left(x^{2}-y^{2}\right)$ orbital energetically.

energetically higher $e_{g}$ level, occupies either a $3 z^{2}-r^{2}$ or an $\mathrm{x}^{2}-\mathrm{y}^{2}$ orbital. Elongation of $\mathrm{MnO}_{6}$ octahedron along the $z$ axis favours the $3 z^{2}-r^{2}$ form (lowering of total energy) and raises the energy of the $x^{2}-y^{2}$ orbital, which is hence less probably occupied (Fig. 2a, b). Vice versa, compression of the $z$-axis results in a widening along the $x$ - and $y$-axes and the $x^{2}-y^{2}$ orbital form becomes favourable (Fig. 2c). When starting from an undistorted octahedron, stretching for example, along the $z$-axis with a displacement $\delta$ has a twofold effect: The potential energy of Coulomb repulsion between the $3 z^{2}-r^{2}$ electron and the $\mathrm{O}^{2-}$ ion decreases approximately proportional to $\delta$ while the elastic-deformation energy rises with $\delta^{2}$. The total energy has therefore a local minimum at an equilibrium deformation $\delta^{*}>0$. For $\mathrm{LaMnO}_{3}$, containing only $\mathrm{Mn}^{3+}, \delta^{*}$ is in the order of $0.15 \AA$ or $4 \%$ of the lattice constant while the achieved energy decrease corresponds to $0.6 \mathrm{eV}$ per unit cell [19].

Perovskites in which each unit cell contains a JT-active ion show characteristic long-range distortions due to a collective arrangement of elongated octahedra. This is known as orbital ordering or cooperative Jahn-Teller effect. In case of $\mathrm{LaMnO}_{3}$ single crystals, Rodríguez-Carvajal et al. found orbital ordering at a transition temperature $T_{\mathrm{JT}} \approx 750 \mathrm{~K}$ using neutron diffraction [20]. Above $T_{\mathrm{JT}}$, the structure is apparently cubic due to equal presence of randomly distributed $x^{2}-y^{2}$ and $3 z^{2}-r^{2}$ orbitals, the latter with a random orientation along the three main crystallographic axes. Below $T_{\mathrm{JT}}$, the elongated distortion form, hosting $3 z^{2}-r^{2}$ orbitals, becomes prevalent. This was identified from a shrinking of the $c$-axis lattice constant with simultaneous expansion of the $b$ axis.

Another perovskite that displays cooperative ordering of Jahn-Teller distortions is $\mathrm{KCrF}_{3}$ in which $\mathrm{Cr}^{2+}$ is the JTactive ion, see Fig. 3 [21]: Using high-resolution synchro tron X-ray diffraction, Margadonna and Karotsis determined the bond lengths between $\mathrm{Cr}^{2+}$ and the six surrounding $\mathrm{F}^{-}$ ions to be uniformly $a=2.116 \AA$ for temperatures above $T_{\mathrm{JT}}=973 \mathrm{~K}$. Analysis of the orbital mixing coefficients revealed a statistically equal occupation of $x^{2}-y^{2}$ - and $3 z^{2}-r^{2}$ orbitals in the high-temperature phase. Below $T_{J T}$, the bonds along one axis expanded to $2.294 \AA$ while those in the two perpendicular directions shrunk to $\approx 1.99 \AA$, indicating

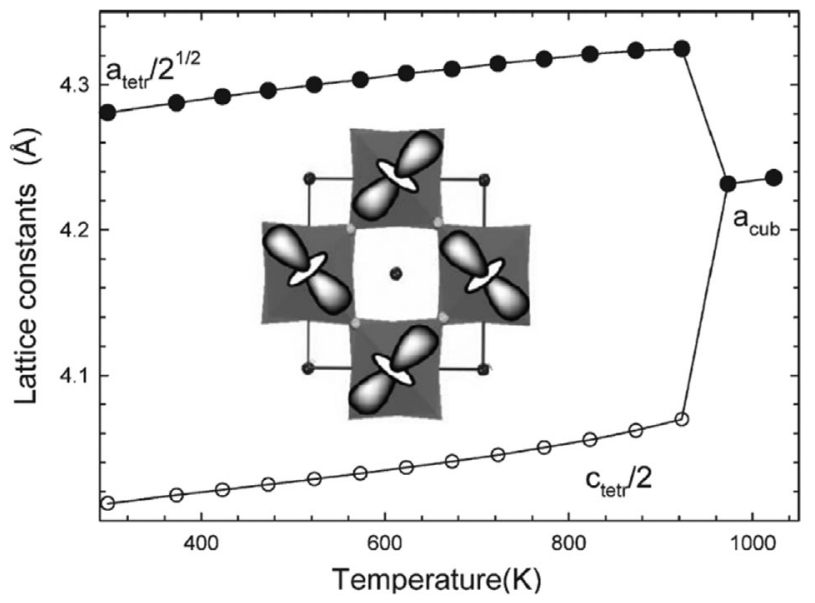

Figure 3 The perovskite $\mathrm{KCrF}_{3}$ with Jahn-Teller-active $\mathrm{Cr}^{2+}$ ions shows a first-order orbital-ordering transition at $T_{\mathrm{JT}}=973 \mathrm{~K}$, resulting in a bifurcation of the lattice constants. The hightemperature phase is cubic while a long-range tetragonal distortion sets in upon cooling below $T_{\mathrm{JT}}$ : The elongated $\mathrm{Cr}^{2+} \mathrm{F}^{6-}$ octahedra form an alternating antiferrodistorsive pattern in the expanding $a b$ plane while the $c$ axis contracts. The volume per formula unit drops upon heating above TJT. Adapted from Ref. [21] with permission of The Royal Society of Chemistry.

the elongated distortion displayed in Fig. 2b. Comparison with the macroscopically determined lattice constants revealed the so-called antiferrodistorsive orbital pattern in the $a b$ plane shown in the insert of Fig. 3. Along the $c$ axis, the orientation of the elongated octahedral axis shows the same alternating pattern as along the $a$ - and $b$-directions [22].

Furthermore, orbital-ordering effects occur in $\mathrm{SrRuO}_{3}$ [23], vanadites such as $\mathrm{LuVO}_{3}[24,25]$ and the manganite $\mathrm{Pr}_{1-x} \mathrm{Sr}_{x} \mathrm{MnO}_{3}$ with $x=0,0.5$, and 0.75 [26]. Hence, orbital ordering can also occur for certain integer ratios between $\mathrm{Mn}^{3+}$ and $\mathrm{Mn}^{4+}$, which is for example, also the case in the layered compound $\mathrm{La}_{0.5} \mathrm{Sr}_{1.5} \mathrm{MnO}_{4}$ [27]. For further reading from an experimental perspective, we refer to the feature article by Goodenough and Zhou [28]. The relationship between orbital ordering and the electronic band structure of perovskites is analysed [29], providing also an overview on a plurality of orbitally ordered structures beyond the antiferrodistorsive ordering addressed above.

2.3 Charge-ordering effects in perovskites This phenomenon can occur in all perovskites in which the B-site cations can attain different ionization states. Historically, it goes back to the Verwey transition discovered in 1939 on magnetite $\left(\mathrm{Fe}_{3} \mathrm{O}_{4}\right.$, spinel-type structure $)[30,31]$. The crystalline unit cell contains eight $\mathrm{Fe}^{3+}$ ions fixed at tetrahedral positions and the octahedral positions are randomly filled with eight $\mathrm{Fe}^{2+}$ - and eight $\mathrm{Fe}^{3+}$ ions. Hence, thermally activated hopping allows for a semiconductor-like conductivity. Upon cooling below the chargeordering temperature $T_{\mathrm{CO}}=125 \mathrm{~K}$, the distribution of $\mathrm{Fe}^{2+}$. and $\mathrm{Fe}^{3+}$ ions freezes into a regular lattice that is stabilized 
by Coulomb repulsion and the resistance shows a jump-like increase by two orders of magnitude.

Within the perovskite context, manganites are the mostly studied charge-ordering compounds. Single crystals of $\mathrm{Pr}_{0.5} \mathrm{Sr}_{0.5} \mathrm{MnO}_{3}$ exhibit $\mathrm{Mn}^{3+}$ - and $\mathrm{Mn}^{4+}$ ions in a 1:1 ratio, resulting in a first-order charge ordering transition $(\mathrm{CO})$ at $T_{\mathrm{CO}} \approx 140 \mathrm{~K}$ as confirmed by resistivity-, magnetization and neutron-diffraction measurements [26, 32]. Similarly, $\mathrm{Nd}_{0.5} \mathrm{Ca}_{0.5} \mathrm{MnO}_{3}$ also has the 1:1 ratio of manganese valencies and $\mathrm{CO}$ occurs at $T_{\mathrm{CO}} \approx 220 \mathrm{~K}$ $[33,34]$. Figure 4 shows the crystallographic structure of the $a b$ plane determined by neutron diffraction with Rietveld refinement at a temperature of $10 \mathrm{~K}$. The checker-board distribution of $\mathrm{Mn}^{3+}$ and $\mathrm{Mn}^{4+}$ is clearly visible and the structure repeats congruently along the $c$ axis. Interestingly, these $\mathrm{CO}$ states can be destroyed by a magnetic field, resulting in the colossal magnetoresistance effects that will be discussed in Section 5. For a detailed overview on charge ordering in manganese perovskites we refer to a review article by Rao et al. [35].

Related to charge ordering is the so-called chargedisproportionation effect, known e.g., for the ferrite-based perovskites $\mathrm{CaFeO}_{3}$ and $\mathrm{SrFeO}_{3}$ [36, 37] and for the nickelate $\mathrm{SmNiO}_{3}$ [38]. These compounds are poor conductors, not insulators, and the conductivity is possibly related to oxygen vacancies. $\mathrm{CaFeO}_{3}$ undergoes a transition to an insulating state below $290 \mathrm{~K}$. The disproportionation mechanism encompasses (formally) a shift of valence electrons in the sense $2 \mathrm{Fe}^{4+} \rightarrow \mathrm{Fe}^{3+}+\mathrm{Fe}^{5+}$, the latter forming practically a covalently bound state with oxygen ions. The disproportionation in the nickelate is supposed to be $2 \mathrm{Ni}^{3+} \rightarrow \mathrm{Ni}^{2+}+\mathrm{Ni}^{5+}$ and the conductivity of the material can be modulated by electron doping at room temperature within eight orders of magnitude [38].

2.4 Double perovskites Many of the structural pecularities discussed so far, and the physical phenomena addressed in the next sections, return in double perovskites with the formula $\mathrm{A}_{2} \mathrm{~B}^{\prime} \mathrm{B}^{\prime \prime} \mathrm{O}_{6}$. Well-known examples are, $\mathrm{Ba}_{2} \mathrm{CaWO}_{6}$ described already in 1972 [39] and $\mathrm{Sr}_{2} \mathrm{FeMoO}_{6}$ showing a strong CMR effect at room temperature $[14,40]$.
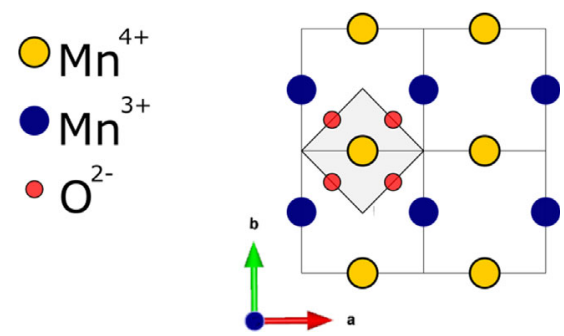

Figure 4 Simplified scheme of the charge-ordered state of $\mathrm{Nd}_{0.5} \mathrm{Ca}_{0.5} \mathrm{MnO}_{3}$ with a checker-board pattern of $\mathrm{Mn}^{3+}$ (blue dots) and $\mathrm{Mn}^{4+}$ ions (yellow) seen along the $c$ axis. The grey-shaded area corresponds to the chemical unit cell illustrated in Fig. 1a. Figure modified from Ref. [34] with permission from AAAS.
In a review from 2015, Vasala and Karppinen indicate that several hundred $\mathrm{B}^{\prime} \mathrm{B}^{\prime \prime}$ combinations are possible when looking only at $\mathrm{Ca}^{2+}, \mathrm{Sr}^{2+}, \mathrm{Ba}^{2+}$ and $\mathrm{La}^{3+}$ as A-site cations [41]. With divalent $A$-site ions $\left(\mathrm{A}^{2+}\right)$ the combination of oxidation states at the $B$ sites can range from $\mathrm{B}^{\prime 1+} / \mathrm{B}^{\prime \prime 7+}$ to $\mathrm{B}^{\prime 4+} / \mathrm{B}^{\prime \prime 4+}$ with the only boundary condition that Goldschmitt's tolerance factor $t$ is close to 1 .

In several double perovskites, including $\mathrm{Sr}_{2} \mathrm{FeMoO}_{6}$, the $\mathrm{B}^{\prime}$ and $\mathrm{B}^{\prime \prime}$ ions arrange in regular superstructures such as the rock-salt ordering shown in Fig. 2c. To account for the alternating $\mathrm{B}^{\prime}-\mathrm{B}^{\prime \prime}$ sequence along all crystal axes, a new tetragonal unit cell (u.c.), containing two formula units, is defined on basis of the cubic u.c. according to $c_{t} \approx 2 a^{\prime}$ and $a_{t} \approx b_{t} \approx \sqrt{ } 2 a^{\prime}$. The corner points can be chosen to be either $\mathrm{B}^{\prime}$ or B" ions. We mention this re-definition, similar to Fig. $2 \mathrm{~b}$, to avoid possible confusion when comparing crystallographic data set from different literature sources. Interestingly, double perovskites do exist in nature, be it not in the form of oxides but as fluorites: The minerals elpasolite $\mathrm{K}_{2} \mathrm{NaAlF}_{6}$ (named after El Paso County, Colorado) and cryolite $\mathrm{Na}_{3} \mathrm{AlF}_{6}$ (mined formerly in Greenland as an aluminium ore) are natural predecessors of the recent class of halide perovskites with their tremendous role in photovoltaics research, see Sect. 8.

2.5 Layered perovskites and the RuddlesdenPopper series Compounds of the Ruddlesden-Popper series (RP) were first described in 1957/58 with the examples of $\mathrm{K}_{2} \mathrm{NiF}_{4}$ and $\mathrm{Sr}_{3} \mathrm{Ti}_{2} \mathrm{O}_{7}$ [42, 43]. Their general formula is $\mathrm{A}_{\mathrm{n}-1} \mathrm{~A}_{2}^{\prime} \mathrm{B}_{\mathrm{n}} \mathrm{X}_{3 \mathrm{n}+1}$ with $\mathrm{B}$ being usually a transition metal ion. As an example for $n=2$ compounds, Fig. $1 \mathrm{~d}$ shows the structure of the bilayer perovskite $\mathrm{LaSr}_{2} \mathrm{Mn}_{2} \mathrm{O}_{7}: \mathrm{MnO}_{6}$ octahedra are stacked in bilayers along the $c$ axis while subsequent bilayers are displaced by $(a / 2, b / 2)$ with respect to each other and separated by $\mathrm{SrO}$ sheets $[15,44]$. A well-known $n=1$ representative of the RP series is $\mathrm{La}_{2} \mathrm{CuO}_{4}$, the parent compound of the hightemperature superconductors discussed in Sect. 5 [9]. At room temperature, the structure is tetragonal with a $c$ axis length of $13.2 \AA$ to accomodate the stacking periodicity along the $c$ direction. The crystallographic unit cell hosts therefore two formula units (f.u.) of this compound [45]. Due to their layered structure in real space, RP compounds often show an anisotropic behavior with respect to electrical conduction and magnetization. With increasing number $n$, especially in the limiting case $n \rightarrow \infty$, we obtain nominally $\mathrm{A}_{\mathrm{n}} \mathrm{B}_{\mathrm{n}} \mathrm{O}_{3 \mathrm{n}}$, which is again the basic cubic structure of Fig. 1a. Such cubic perovskites respond isotropically to applied electric- or magnetic fields.

A complete overview of crystallographic and other aspects of perovskites and related compounds is given in the book 'Perovskites: Modern and Ancient' by R. H. Mitchell [46].

3 Preparation methods for perovskites Most synthesis methods addressed within this section can be employed for multiple subtypes of perovskite-based 
materials. However, mainly in case of thin-film samples, the properties of a specific material such as its electrical conductivity, chemical reactivity or crystallographic stacking make certain preparation techniques favourable. For each method we give compounds as examples that are often synthesized with the respective route, non-withstanding that also other techniques may be applicable. Thin-film deposition by sputtering is, for example, widely used for cuprates, laser-ablation for manganites and sol-gel techniques for the halide perovskites. More information on thinfilm deposition techniques for complex perovskite-type oxides can be found in a review by H.-U. Habermeier [47]. Towards perovskite-based photovoltaic applications, various wet deposition techniques are applied for future low cost and large area processing.

3.1 Single crystals To observe phenomena such as charge- and orbital ordering, or any other kind of phase transition, samples with high chemical purity and nondistorted crystalline structure are mandatory. Single-crystals are therefore the sample type of choice and practically all established growth techniques are employed in perovskite context, starting from polycrystalline powder- or bulk material. These polycrystalline precursors are, in most cases, obtained by high-temperature solid-state reactions (sintering) between oxides and/or carbonates of the respective metals. For oxide-based perovskites, the required temperatures for single-crystal synthesis typically exceed $1000^{\circ} \mathrm{C}$. Examples include the Verneuil- or 'flame fusion' technique for Nb-doped $\mathrm{SrTiO}_{3}$ [48] and the Czochralski method (the industry standard for producing silicon wafers) for $\mathrm{GdGaO}_{3}$ and $\mathrm{NdAlO}_{3}[49,50]$. The floating-zone method is reported for $\mathrm{LaMnO}_{3}$ and $\mathrm{SrRuO}_{3}$ [51, 52] and also for the layered perovskite $\mathrm{La}_{1-x} \mathrm{Sr}_{1+x} \mathrm{MnO}_{4}$, an $n=1$ member of the RP structural series [53]. The Bridgman method or 'directed solidification' is appropriate for piezoelectric lead perovskites with complex B-site compositions such as $\mathrm{Pb}\left[\left(\mathrm{Mg}_{1 / 3} \mathrm{Nb}_{2 / 3}\right)_{0.60} \mathrm{Ti}_{0.40}\right] \mathrm{O}_{3}$ [54]. Also for the halide perovskite $\mathrm{CsPbBr}$, a material for $\mathrm{X}$ - and $\gamma$-ray detection, the Bridgman method is suitable, requiring only reaction temperatures of $600^{\circ} \mathrm{C}$ [55]. Recently, single crystals of the organo-metal halide perovskite $\mathrm{MAPbX}_{3}$ (MA denotes methyl ammonium $\mathrm{CH}_{3} \mathrm{NH}_{3}{ }^{+}$and $\mathrm{X}$ stands for $\mathrm{Br}^{-}$or $\mathrm{I}^{-}$) were grown directly from a solution using a novel process termed 'inverse temperature crystallization' [56]. The precursors are hereby dissolved in an organic solvent and reaction temperatures do not exceed $80^{\circ} \mathrm{C}$.

\subsection{Thin-film preparation - general aspects}

Perovskites in the form of thin films, typically with a thickness below $1 \mu \mathrm{m}$, are a favourable sample type for fundamental- and applied research: A thin film is a first step towards integrating the material in microelectronic circuits and, in case of epitaxial films, the specimen displays properties coming close to the purity of single crystals. A decisive point is the choice of substrate onto which the perovskite layer is deposited [47]: This substrate should be inert in oxidizing- and reducing atmospheres at elevated deposition temperatures ranging in exceptional cases up to $1000{ }^{\circ} \mathrm{C}$. The lattice parameters of the substrate should fit those of the perovskite capping layer to allow for epitaxy and their thermal expansion coefficients should match (typically in the order of $10^{-5} \mathrm{~K}^{-1}$ ). Interdiffusion must be negligible to avoid unintentional doping of the top layer and the substrate should not undergo structural transitions in the temperature window between deposition- and application. The latter might cause artefacts regarding the measured properties of the perovskite top layer to be studied, just as all other properties in which the substrate (typical thickness of $1 \mathrm{~mm}$ ) can overwhelm the characteristics of the submicrometer perovskite layer. Especially data on magnetic and dielectric properties of thin perovskite films may be compromised by the response of the substrate.

These demands make that commonly used substrate materials are oxides themselves and not silicon or metals, which would necessitate an interlayer as inert diffusion barrier. Metallic substrates for deposition of cuprate superconductors are addressed in Section 5.3. Among the oxides, we mention $\mathrm{MgO}$ (cubic, lattice constant $a=4.212 \AA$ at room temperature, $\mathrm{RT}$ ), $\mathrm{LaAlO}_{3}$ (pseudocubic, $a=3.787 \AA$ ), $\mathrm{LaGaO}_{3}$ (orthorhombic, $a=5.519 \AA$, $b=5.494 \AA, c=7.777 \AA$ [57]) and $\mathrm{SrTiO}_{3}$ (cubic, $a=3.905 \AA$ ). $\mathrm{SrTiO}_{3}$ shows a transition to a tetragonal structure upon cooling below $110 \mathrm{~K}$, but this does not impede its popularity as a versatile substrate for all kinds of studies on perovskite thin films [58]. Due to the possibility of growing epitaxial films in situ, meaning that the correct phase forms during film deposition, we focus first on vacuum-based physical vapour deposition (PVD).

\subsection{Thin-film preparation by sputtering Sput-} tering deposition is based an autonomous gas discharge maintained between a usually disk-shaped, sintered polycrystalline target (held at a negative d.c. potential of several hundred Volts) and a substrate kept at ground potential. Modifications include the use of radiofrequency potentials for electrically insulating target materials and specific arrangements of magnetic fields (magnetron) to enhance the film-deposition rate and to confine the plasma close to the target surface. Several review articles on sputtering techniques are available in literature, including Refs. $[59,60,61]$. In general, positive ions of the discharge plasma impinge on the target, thereby releasing mainly neutral atoms which condense as a solid film on the substrate. To achieve the desired phase in situ, the substrate is heated to typically $700-900^{\circ} \mathrm{C}$ for HTSC cuprates and, depending on the material and crystalline orientation of the substrate, epitaxial growth of the perovskite layer is obtained. Versatile substrates for most HTSC compounds are (100)-oriented single-crystalline $\mathrm{SrTiO}_{3^{-}}$and $\mathrm{LaAlO}_{3}$ chips: Their cubic structure matches well with the $a$ - and $b$ lattice constants of the tetragonal or orthorhombic cuprates (see Sect. 5), inducing a preferential $c$-axis oriented film growth. A second condition for achieving the correct phase 
in situ is the presence of oxygen in the sputtering gas, described as 'reactive sputtering'. Poppe et al. have introduced the use of pure oxygen at the unconventionally high pressure of $3.3 \mathrm{hPa} \mathrm{O}_{2}$ for the deposition of $\mathrm{YBa}_{2} \mathrm{Cu}_{3} \mathrm{O}_{7-\delta}$ [62]. This way, the presence of oxygen vacancies in the perovskite lattice is significantly reduced. Due to the short mean free path, atoms from the gas atmosphere arrive on the substrate with strongly reduced energy, thus avoiding undesired mixing- and re-sputtering effects. Thereafter, the concept of high-pressure sputtering was transferred to other cuprate superconduc tors including $\mathrm{Bi}_{2} \mathrm{Sr}_{2} \mathrm{CaCuO}_{8+\delta}$ [63], $\mathrm{Bi}_{2} \mathrm{Sr}_{2} \mathrm{Ca}_{2} \mathrm{Cu}_{3} \mathrm{O}_{10+\delta}$ [64], and $\mathrm{La}_{2-x} \mathrm{Sr}_{x} \mathrm{CuO}_{4}$ [65]. In order to maximize the superconducting critical temperature $T_{\mathrm{c}}$, the slight excess or deficiency $\delta$ of oxygen atoms at interstitial positions can be adjusted by post-deposition thermal annealing in oxidizing or reducing atmosphere.

\subsection{Thin-film preparation by laser ablation This} technique, also known as pulsed laser deposition PLD, is based on the local vaporization of a solid, pellet-shaped target by an intense laser beam, see Fig. 5. Unlike d.c. sputtering, PLD is also applicable to deposit electrically poorly conducting (e.g., manganites) or even insulating materials. Excimer lasers with nanoseconds pulse duration deposit a power input corresponding to several hundred MW on a $1 \mathrm{~mm}^{2}$ spot on the target. Therefore, evaporation of molten target material to a plasma plume happens considerably faster than the transport of thermal energy across the target surface. For an overview on the interactions between laser beams and solids we refer to the review article by Willmott and Huber [66]. In case of perovskites and other oxides, the film-deposition rates achieved with PLD are in the order of $100 \mathrm{~nm} \mathrm{~min}^{-1}$, thus considerably faster than the typical $100 \mathrm{~nm} \mathrm{~h}^{-1}$ obtained with sputtering. However, due to the limited diameter of the plasma plume, PLD is less suited for large-area deposition and substrate surfaces are limited to a few square centimetres. On the other hand, the narrow

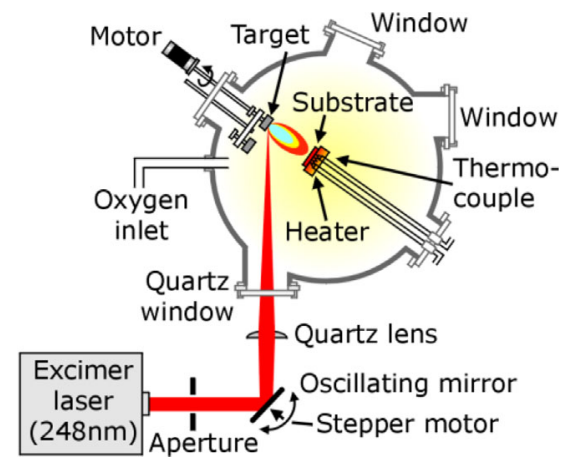

Figure 5 Scheme of a pulsed-laser system for depositing a variety of oxide materials and multilayers by ablation from several targets. The heated substrate and presence of oxygen allow for in situ formation of the desired compound. Figure reproduced from Ref. [68]. laser-beam diameter and the compact size of ablation targets allow placing several targets in close vicinity: By hitting the targets in a specific order during specific times, complex stacks of oxide materials can be built up sequentially, if necessary down to the scale of discrete crystal-lattice planes. This layer-wise deposition is known as 'laser-MBE' [67] and was employed for preparing perovskite-perovskite interfaces discussed in Sect. 5.5.

There are numerous literature articles on perovskite thinfilms deposited by PLD from single, stoichiometrically composed targets. A few examples include: The manganites $\mathrm{La}_{0.67} \mathrm{Ba}_{0.33} \mathrm{MnO}_{3}, \quad$ [8] $\mathrm{La}_{0.67} \mathrm{Ca}_{0.33} \mathrm{MnO}_{3}$ [69], and $\mathrm{La}_{0.7} \mathrm{Ce}_{0.3} \mathrm{MnO}_{3}$ [70]; the nickelate $\mathrm{NdNiO}_{3}$ [71]; the titanates $\mathrm{SrTiO}_{3}$ [72] and $\mathrm{Ba}_{0.25} \mathrm{Sr}_{0.75} \mathrm{TiO}_{3}$ [73]; the cobaltate $\mathrm{LaCoO}_{3}$ [74]; and the chromate $\mathrm{BiCrO}_{3}$ [75]. Also, films of the double perovskites $\mathrm{Sr}_{2} \mathrm{FeMoO}_{6}$ [76] and $\mathrm{La}_{2} \mathrm{NiMnO}_{6}$ [77] were deposited by PLD from single targets. By using two different targets with sequential deposition, multilayers of $\mathrm{BaTiO}_{3-}$ and $\mathrm{BiFeO}_{3}$ were successfully prepared [78] as well as $\mathrm{SrTiO}_{3}-\mathrm{LaAlO}_{3}$ multilayers [79].

\subsection{In situ engineering of materials properties}

Vacuum-deposition techniques such as sputtering and laser ablation allow controlling the electronic properties of perovskite films in a rather broad range. This is accomplished via the process gas used during and after deposition and by the choice of substrate material that exerts compressive or tensile strain on the growing perovskite layer. As an example, superconductors, discussed in more detail in Section 5, show commonly an increase of their critical temperature under hydrostatic pressure. In case of thin films, this mechanism can be mimicked by compressive strain. $\mathrm{La}_{1.9} \mathrm{Sr}_{0.1} \mathrm{CuO}_{4}$ in bulk form, hence unstrained, is tetragonal with $a=3.784 \AA$ $(c=13.212 \AA)$ and $T_{\mathrm{c}}=25 \mathrm{~K}$. Locquet et al. deposited this compound on $\mathrm{SrLaAlO}_{4}$ substrates with an in-plane lattice constant of $3.754 \mathrm{~A}$ to induce compressive strain and found a spectacular doubling of the critical temperature to $49 \mathrm{~K}$ [80]. Vice versa, when depositing $\mathrm{La}_{1.9} \mathrm{Sr}_{0.1} \mathrm{CuO}_{4}$ under identical conditions onto $\mathrm{SrTiO}_{3}$ substrates, tensile strain occurs that reduces $T_{\mathrm{c}}$ down to $10 \mathrm{~K}$. Similarly, it was shown that the Curie temperature and magnetic susceptibility of ferromagnetic $\mathrm{LaCoO}_{3}$ can be controlled by substrate-induced strain [74]. The strain values imposed by an intentional lattice misfit are substantially higher that than those obtained conventionally by uniaxial pressure. However, tuning the properties of a perovskite film by 'strain engineering' is limited to ultrathin films with thicknesses not exceeding ca. $10-100 \mathrm{~nm}$. In case of thicker film, stress is released by the formation of dislocations and the physical properties of the film will again resemble those of the corresponding bulk material.

Presence of oxygen in the process gas is a necessity during film formation of oxides, but a deliberate fine tuning of the oxygen contents is most efficiently done by postdeposition annealing. In case of the superconductor 
$\mathrm{YBa}_{2} \mathrm{Cu}_{3} \mathrm{O}_{7-\delta}$, the oxygen deficiency $\delta$ should be $\delta \rightarrow 0$ to achieve the maximum $T_{\mathrm{c}}$ of $92-94 \mathrm{~K}$, see also Sect. 5 . Hence, annealing with $p\left(\mathrm{O}_{2}\right)$ close to atmospheric pressure at deposition temperature followed by slow cooling to RT is the method of choice, which can be further improved by ozone annealing. More complex is the situation with $\mathrm{Bi}_{2} \mathrm{Sr}_{2} \mathrm{CaCu}_{2} \mathrm{O}_{8+\delta}$ containing $8 \mathrm{O}^{2-}$ ions per f.u. at lattice sites and loosely bound interstitial oxygen. The maximal $T_{\mathrm{c}}$ of ca. $90 \mathrm{~K}$ occurs for $\delta \approx 0.26$, which was accomplished by a two-step annealing with first filling-up the lattice sites (at $\left.830^{\circ} \mathrm{C}, \quad p\left(\mathrm{O}_{2}\right)=100 \mathrm{hPa}\right)$, followed by adjusting the interstitial oxygen $\delta\left(500^{\circ} \mathrm{C}, p\left(\mathrm{O}_{2}\right)=10^{-2} \mathrm{~h} \mathrm{~Pa}\right)$ [81]. In case of manganites such as $\mathrm{La}_{0.7} \mathrm{Ce}_{0.3} \mathrm{MnO}_{3}$ films, there is evidence that as-grown specimens do not show oxygen deficiency but, instead, an oxygen excess, which results in an effective hole doping [70]. To remove this excess and to reduce the oxygen concentration further, high-temperature annealing in ultrahigh vacuum (e.g., $10^{-9} \mathrm{hPa}$ at $700^{\circ} \mathrm{C}$ ) can be employed for several hours. As a result, the conductivity can be varied by orders of magnitude, the insulator-to-metal transition upon cooling can be suppressed, and new features arise including photoconductivity and electro-resistive effects [70, 82].

3.6 Chemical solution deposition Fabrication via solution- or 'wet' deposition opens the way for a variety of relatively simple and low-cost processing routes, from ultrasonic spray coating to a variety of printing techniques. Organometal halide-perovskite photovoltaics (further discussed in Section 8) owe much of the success they obtained over the last few years to their compatibility with such wet deposition methods. High power conversion efficiencies of more than $10 \%$ were reported for spin-, spray-, slot die-, blade- and drop-coated solar cells [83-85]. In general, wet deposition processes can be divided into two main groups, termed one-step and two-step methods [86]:

The first successful one-step method to deposit highquality $\mathrm{CH}_{3} \mathrm{NH}_{3} \mathrm{PbI}_{3-x} \mathrm{Cl}_{x}$ films, introduced by Lee et al. [87], used a dimethylformamide (DMF) precursor solution of $\mathrm{PbCl}_{2}$ and $\mathrm{CH}_{3} \mathrm{NH}_{3} \mathrm{I}$ with a 1:3 molar ratio and a typical annealing temperature of $100{ }^{\circ} \mathrm{C}$, yielding polycrystalline perovskite films with $100-1000 \mathrm{~nm}$ grain sizes. To this date, several protocols have been developed, involving a variety of $\mathrm{Pb}$ salts as main inorganic precursors to dissolve in $\mathrm{DMF}$ or dimethyl sulfoxide (DMSO), with or without successive solvent/gas annealing steps to incorporate iodide into the $\mathrm{PbI}_{2}$ film [86, 88-90]. A key challenge with this one-step method is that the morphology and quality of the resulting films are mainly determined by the shrinking of the film due to the simultaneous removal of excess solvent through evaporation and crystallization of perovskite [86]. In a typical two-step method, a $\mathrm{PbI}_{2}$ precursor layer is first deposited on a substrate and methylammonium iodide is then diffused into the previous layer from a solution in propanol, isopropanol or similar [91, 92]. Points of attention with this approach are the volume expansion and efficient diffusion of methyl ammonium.
Besides the mentioned wet deposition methods, it has to be noted that physical (PVD) and chemical (CVD) vapour deposition methods are also being investigated for photovoltaic applications. Planar perovskite solar cells from dual-source PVD were demonstrated by Liu et al. [93] and by Momblona et al. [94] using $\mathrm{PbCl}_{2}$ or $\mathrm{PbI}_{2}$ as inorganic source, while Leyden et al. employed CVD to obtain uniform $\mathrm{CH}\left(\mathrm{NH}_{2}\right)_{2} \mathrm{PbI}_{3}$ films on large areas [95].

Chemical solution deposition is also in use for preparing oxide-perovskite layers given the advantage that wet processes are less expensive than the PVD techniques and allow to coat surfaces of arbitrary shape and size. Phase formation is hereby achieved through postdeposition annealing treatments, resulting often in polycrystalline specimens. Notwithstanding, crack-free and well textured films of the piezoelectric perovskite $\mathrm{PbZr}_{x} \mathrm{Ti}_{1-x} \mathrm{O}_{3}$ on silicon substrates could be prepared [96]. For an overview on chemical solution deposition methods for perovskites (sol-gel-, chelate- and metallo-organic decomposition methods), we refer to a review article by Schwartz [97].

4 Colossal negative magnetoresistance This is historically one of the 'oldest' unexpected effects in perovskites, dating back to 1954 , when J. Volger stud ied resistance and magnetization of polycrystalline $\mathrm{La}_{1-\delta} \mathrm{Sr}_{\delta} \mathrm{MnO}_{3}$ specimens, see Fig. 6 [7]. The topic revived when von Helmolt et al. discovered in 1993 a magnetic-field induced 60\% resistance drop in epitaxial $\mathrm{La}_{0.67} \mathrm{Sr}_{0.33} \mathrm{MnO}_{3}$

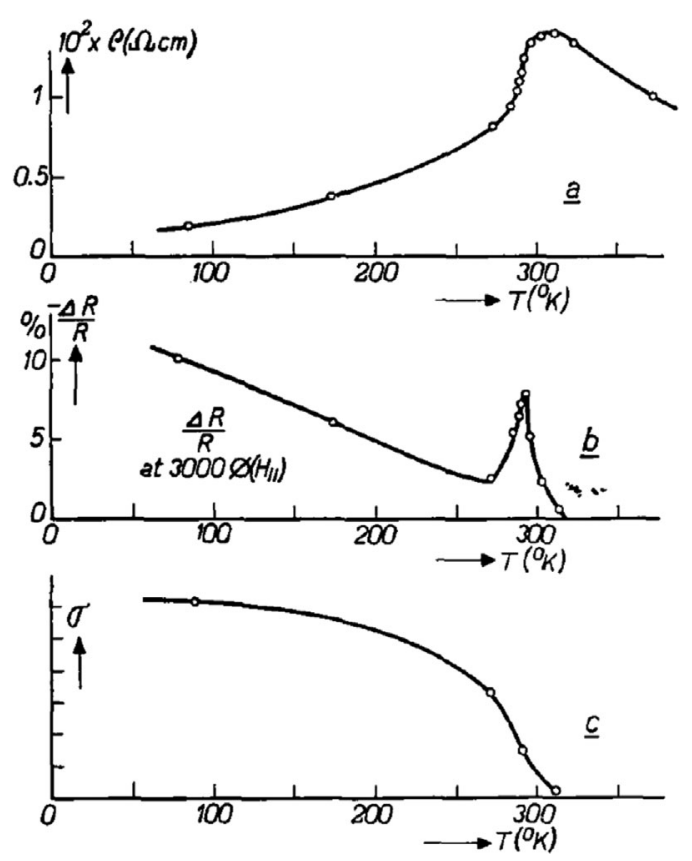

Figure 6 Temperature dependence of the resistance $\rho$ (a), the relative magnetoresistance $\Delta R / R$ (b), and the magnetization (c) of polycrystalline $\mathrm{La}_{0.8} \mathrm{Sr}_{0.2} \mathrm{MnO}_{3}$ published by $\mathrm{J}$. Volger in 1954. Figure reproduced from Ref. [6] with permission by Elsevier. 


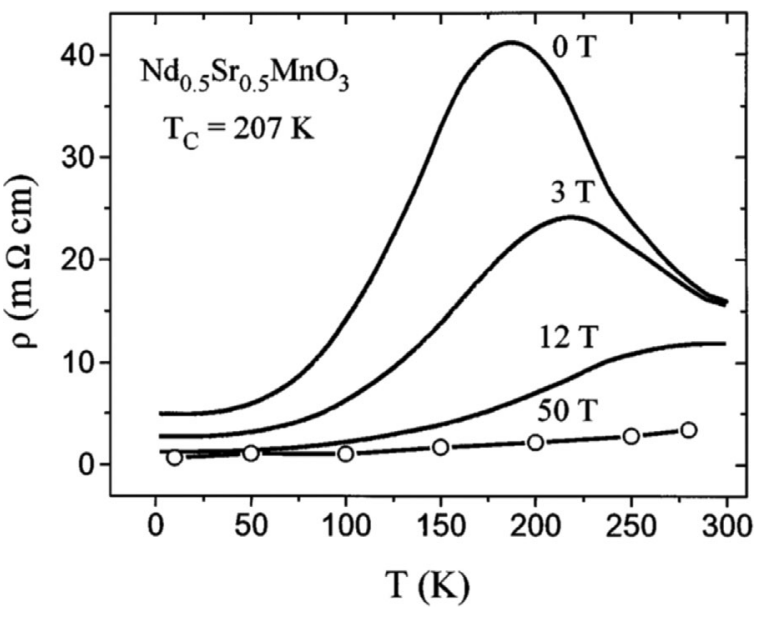

Figure 7 Temperature- and magnetic-field dependence of the resistivity $\rho$ of an epitaxial $\mathrm{Nd}_{0.52} \mathrm{Sr}_{0.48} \mathrm{MnO}_{3}$ thin film. Data symbolized by open dots were obtained in pulsed magnetic fields. The resistance drop $\Delta \rho(\mathrm{B})$ at any given temperature $\mathrm{T}$ follows Eq. (2). Figure reprinted with permission from Ref. [101] Copyright (2017) by the American Physical Society.

films [8]. In 1995, Tomioka and co-workers found a drop by two orders of magnitude in $\operatorname{Pr}_{1 / 2} \mathrm{Sr}_{1 / 2} \mathrm{MnO}_{3}$ single crystals and explained this by a field-induced melting of a chargeordered state formed by the equal ratio of $\mathrm{Mn}^{3+}$ and $\mathrm{Mn}^{4+}$ [32]. The phenomenon was coined 'colossal negative magnetoresistance CMR' in analogy to the giant negative magnetoresistance GMR: In 1986, P. Grünberg and co-workers discovered the antiferromagnetic coupling between iron layers separated by a non-ferromagnetic chromium spacer [98]. Soon after, A. Fert et al. observed that magnetic alignment of the Fe layers by an external field causes a substantial resistance drop of $45 \%$ [99]. Fert and Grünberg were awarded with the Nobel Prize in Physics in 2007 for the 'discovery of giant magnetoresistance' and GMR plays today a key role in magnetic read \& write heads, data storage and random-access memories.
CMR is until date not used commercially because magnetic fields of several Tesla are required at RT to induce measurable resistance drops, which are evidently incompatible with magnetic data storage, see Fig. 7. Nevertheless, CMR manganites show resistance drops of up to six or even more orders of magnitude and the underlying magnetoresistance mechanisms, discussed further below, exhibit similarities with the GMR effect. Table 1 summarizes the CMR ratio of selected Mn-perovskites together with CMRand permalloy-based magnetic-field sensors. To facilitate the comparison between different literature sources, we define the CMR ratio uniformly as the ratio between the absolute resistance of a sample (measured for a given temperature and magnetic field) and the zero-field (ZF) resistance at this temperature. For completeness, we mention that resistance drops in the order of $30 \%$ can be achieved in fields well below $200 \mathrm{mT}$ by employing grainboundary magnetoresistance, but this requires still cryogenic temperatures [100].

4.1 Mechanisms underlying the CMR effect The mother compounds of mixed-valency manganites such as $\mathrm{LaMnO}_{3}$ and $\mathrm{SrMnO}_{3}$ are insulators with an antiferromagnetic ordering between neighbouring $\mathrm{Mn}$ sites. The ordering results from the super-exchange mechanism which can be illustrated in a sequence of e.g., $\mathrm{Mn}^{3+}-\mathrm{O}^{2-}-\mathrm{Mn}^{3+}$ :

Both electrons in the $\mathrm{O}^{2-} 2 \mathrm{p}$-orbital along the bond have opposite spin directions and, due to orbital overlap with the $3 \mathrm{~d}$ electrons of the $\mathrm{Mn}$ ions, the magnetic moments of these ions will also point into opposite directions. The double-exchange (DE) mechanism, proposed 1951 by C. Zener, explains ferromagnetism and metallic-like conductivity of mixed-valency manganites in a dynamic picture [105]: In the sequence $\mathrm{Mn}^{3+}-\mathrm{O}^{2-}-\mathrm{Mn}^{4+}$ (both Mn ions have the same spin direction), a $2 \mathrm{p}$ electron of $\mathrm{O}^{2-}$ shifts to $\mathrm{Mn}^{4+}$, turning it to $\mathrm{Mn}^{3+}$. The initial $\mathrm{Mn}^{3+}$ becomes $\mathrm{Mn}^{4+}$ by releasing an electron to the intermediate oxygen site. As a net effect, one electron is transferred without changing its spin direction and the dynamic state is energetically

Table 1 Ratio between the resistivity $\rho(B)$ and the zero-field resistivity $\rho(Z F)$ at a given temperature and magnetic field for selected CMR perovskites ${ }^{\mathrm{a}}$ and reference compounds.

\begin{tabular}{|c|c|c|c|c|}
\hline compound & sample type ${ }^{b}$ & CMR ratio $\rho(\mathrm{B}) / \rho(\mathrm{ZF})$ & T B & reference \\
\hline $\mathrm{La}_{0.8} \mathrm{Sr}_{0.2} \mathrm{MnO}_{3}$ & $\mathrm{pc}$ & 0.92 & $\begin{array}{l}295 \mathrm{~K} \\
\quad 300 \mathrm{mT}\end{array}$ & {$[7]$} \\
\hline $\mathrm{La}_{0.67} \mathrm{Ba}_{0.33} \mathrm{MnO}_{3}$ & etf & 0.40 & $300 \mathrm{~K} 7 \mathrm{~T}$ & {$[8]$} \\
\hline $\mathrm{La}_{0.67} \mathrm{Ca}_{0.33} \mathrm{MnO}_{3}$ & etf & $7.9 \cdot 10^{-4}$ & $77 \mathrm{~K} 6 \mathrm{~T}$ & [69] \\
\hline $\mathrm{Nd}_{0.52} \mathrm{Sr}_{0.48} \mathrm{MnO}_{3}$ & etf & 0.05 & $200 \mathrm{~K} 50 \mathrm{~T}$ & [101] \\
\hline $\mathrm{Sr}_{2} \mathrm{FeMoO}_{6}$ & $\mathrm{pc}$ & $\approx 0.70$ & $4.2 \mathrm{~K} 7 \mathrm{~T}$ & {$[14]$} \\
\hline$\left(\mathrm{La}_{0.4} \mathrm{Pr}_{0.6}\right)_{1.2} \mathrm{Sr}_{1.8} \mathrm{Mn}_{2} \mathrm{O}_{7}$ & $\mathrm{sc}$ & $<10^{-6}$ & $5 \mathrm{~K} 3 \mathrm{~T}$ & [102] \\
\hline$(\mathrm{Fe} 3.0 \mathrm{~nm} / \mathrm{Cr} 0.9 \mathrm{~nm})_{40}$ & $\mathrm{mml}$ & 0.55 & $4.2 \mathrm{~K} 2 \mathrm{~T}$ & [99] \\
\hline Commercial GMR sensors & $\mathrm{mml}$ & 0.88 & $293 \mathrm{~K} 3 \mathrm{mT}$ & {$[103]$} \\
\hline Permalloy $80 \% \mathrm{Ni}, 20 \% \mathrm{Fe}$ & $\mathrm{ma}$ & $0.97-0.98$ & $293 \mathrm{~K}<10 \mathrm{mT}$ & [104] \\
\hline
\end{tabular}

${ }^{\mathrm{a} D a t a}$ correspond to the maximal CMR effect found within the temperature range studied in the respective reference.

bc, polycrystal; etf, epitaxial thin film; sc, single crystal; mml, metal multilayer; ma, metal alloy. 
favourable due to the lower kinetic energy of delocalized electrons. At temperatures close to the Curie point $T_{\mathrm{C}}$ of such materials, external magnetic fields are especially efficient to enforce a common direction of the magnetic moments at the $\mathrm{Mn}$ sites, enhancing therefore the DE interaction and electrical conductivity. Besides of this qualitative understanding of CMR, more refined models have been developed and supported by advanced experimental techniques.

In 1998, Wagner and Moshchalkov proposed the spin-dependent hopping model to describe the temperature- and field dependence of the field-induced resistivity decrease of $\mathrm{Nd}_{0.52} \mathrm{Sr}_{0.48} \mathrm{MnO}_{3}$ films with $T_{\mathrm{C}}=207 \mathrm{~K}$ [101]. Given the low carrier mobility of manganites, authors started from Mott hopping as underlying transport mechanism and added a contribution to the energy barrier $W_{i j}$ which depends on the relative orientation of magnetic moments at the initial and final sites of a hopping event. The scaling law for the resistance decrease $\Delta \rho$ is given by:

$$
\Delta \rho(B, T)=A(T) \mathcal{B}^{\alpha}\left(\frac{\mathrm{g} \mu_{\mathrm{B}} J(\mathrm{~T}) \mathcal{B}}{k_{\mathrm{B}} T}\right)
$$

Here, $A(T)$ is an amplitude factor close to the zero-field resistance shown in Fig. $7, \mathcal{B}$ stands for the Brillouin function and $\alpha=1$ in the ferromagnetic (FM) state while $\alpha=2$ in the paramagnetic (PM) phase. $J(T)$ is the average magnetic moment at the hopping sites, $\mu_{\mathrm{B}}$ is the Bohr magneton, and $g=2$ the gyromagnetic ratio. In other words: At a given temperature $T, \Delta \rho$ scales either linearly with the sample magnetization $M(\mathrm{FM})$ or proportional to $M^{2}$ (PM state). This scaling proved correct between $10 \mathrm{~K}$ and room temperature in a broad field range up to 50 Tesla, generated with a pulsed-fields technique. Regarding the magnetic moment, $J$ values up to 60 were found around $T_{\mathrm{C}}$, decreasing rapidly for higher and lower temperatures: This indicates the presence of superparamagnetic spin clusters with a diameter of ca. A total of $10 \mathrm{~A}$ in agreement with earlier observations by De Teresa and co-workers [106]. Similarly, Jakob et al. analysed the magnetotransport properties of $\mathrm{La}_{0.67} \mathrm{Ca}_{0.33} \mathrm{MnO}_{3}$ and, in the paramagnetic regime from $250-600 \mathrm{~K}$, they found non-adiabatic small-polaron hopping to be in best agreement with experimental data. Interestingly, also here evidence was found for the presence of pre-aligned spin clusters comprising 4-6 unit cells [107].

Besides of the analytical models that link $\Delta \rho(B, T)$ with the sample magnetization, imaging techniques gave evidence that phase-separation may also contribute to the colossal resistance changes. Local fluctuations in cation composition suffice to induce a complex pattern of conductive- and insulating regions and these electronic properties correlate in turn with the magnetic and orbital arrangement at the nanoscale. Fiebig et al. have shown that persistent resistive switching can be induced by illumination with light [108]: At $30 \mathrm{~K}, \mathrm{Pr}_{0.7} \mathrm{Ca}_{0.3} \mathrm{MnO}_{3}$ crystals are in an insulating, charge ordered state with canted spins and $10^{9} \Omega$ sample resistance. Illumination with a pulsed infrared laser, to destroy locally the ordered and insulating state, caused a resistance drop by seven orders of magnitude. Interestingly, the conductive regions formed percolating paths as verified by reflectivity imaging. Percolation may therefore play a key role in the spectacularly high CMR amplitudes commonly described as a metal-insulator transition (MIT). This viewpoint was also supported by scanning-tunnelling spectroscopy (STS) on epitaxial $\mathrm{La}_{0.73} \mathrm{Ca}_{0.27} \mathrm{MnO}_{3}$ thin films at temperatures close to $T_{\mathrm{C}} \approx 220 \mathrm{~K}$, see Fig. 8 adapted from Ref. [109] Upon increasing the external magnetic field from ZF to nine Tesla, regions with metallic-like conductivity grow and form percolating networks on the expense of shrinking semiconducting and insulating areas.

4.2 Hall-effect features in manganites Although it is now accepted that CMR is based on a field-induced enhancement of the carrier mobility $\mu$ it took time to confirm that the carrier concentration $n$ is independent of the B field. In his original work, Volger made an interesting statement: 'From Hall effect measurements no conclusions could be drawn except that the apparent electron mobility is extremely small [7]. Today, it is clear that two distinct complications come into play, for which the foundations were laid around 1970. As in other magnetic conductors, the Hall signal contains an anomalous contribution and can be described by $[110,111]$ :

$$
\rho_{x y}=U_{H} \cdot \frac{t}{I}=R_{A} \mu_{0} M+R_{H} B
$$

The first part with the anomalous Hall coefficient $R_{\mathrm{A}}$ scales with the field-dependent magnetisation $M$ of the sample and its sign is equal or opposite to the sign of the dominant charge carriers. $R_{\mathrm{A}}$ can be explained by skew-scattering,
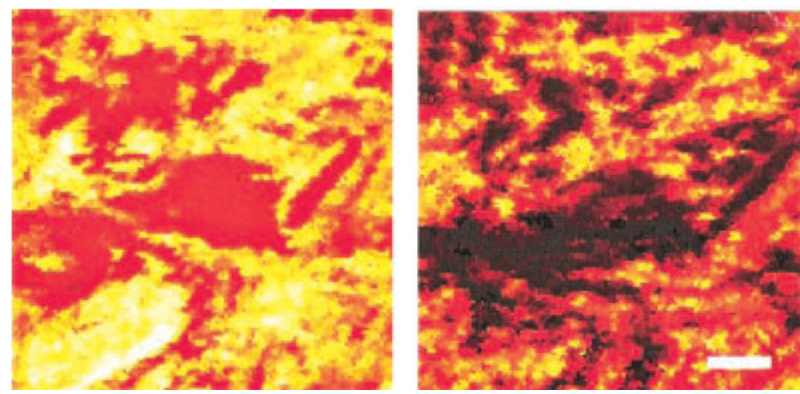

Figure 8 STS micrograph of the spatially inhomogeneous MIT of a $\mathrm{La}_{0.73} \mathrm{Ca}_{0.27} \mathrm{MnO}_{3}$ film close to TC. The left image is at zero field and the right at $B=9 \mathrm{~T}$, both with a frame of $0.61 \times 0.61 \mathrm{\mu m}^{2}$. Light colors indicate insulating areas; red regions show intermediate conductivity and brown-black regions behave metallic-like. Figure adapted from Ref. [109], reprinted with permission from AAAS. 
being a left-right asymmetry in the scattering probability of carriers at localized magnetic moments, possibly in combination with side jumps [112]. The latter is a sideward displacement of the carriers in the order of $10^{-13} \mathrm{~m}$ upon each scattering event. Determining the carrier density $n$ from the ordinary Hall contribution $R_{\mathrm{H}}=(e n)^{-1}$ requires that the magnetization $M(B, T)$ is either measured or calculated from a Curie-Weiss law. Most reliable is working with a saturated sample magnetization $M_{\text {sat }}$ obtained in sufficiently high fields in the ferromagnetic state.

The second complication arises from the fact that electronic transport in manganites can be based on hole- and electron-type charge carriers at the same time. This is described in a two-band model in which the measured Hall voltage depends on the respective concentrations $\left(n_{h}, n_{e}\right)$ and mobilities $\left(\mu_{h}, \mu_{e}\right)$ of both carrier types. The Hall resistance in such a 'compensated' situation is given by the following equation [111].

$$
R_{H}=\frac{1}{e} \frac{\left(n_{h} \mu_{h}^{2}-n_{e} \mu_{e}^{2}\right)}{\left(n_{h} \mu_{h}+n_{e} \mu_{e}\right)^{2}}
$$

First measurements on epitaxial $\operatorname{Pr}_{0.5} \mathrm{Sr}_{0.5} \mathrm{MnO}_{3}$ films pointed to a temperature-independent carrier concentration of $\approx 0.82$ holes per formula unit in the one-band model with a zero-field mobility $\mu \approx 5 \cdot 10^{-2} \mathrm{~cm}^{2} \mathrm{~V}^{-1} \mathrm{~s}^{-1}$ [110]. More refined data on $\mathrm{Nd}_{0.5} \mathrm{Sr}_{0.5} \mathrm{MnO}_{3}$ films $\left(T_{\mathrm{C}}=225 \mathrm{~K}\right)$ gave carrier concentrations of 0.30 holes per f.u. in the PM state, 0.49 holes per f.u. in the FM state, and a local minimum of the carrier concentration around $T_{\mathrm{C}}$ [113]. From the ratio between $\mathrm{Nd}^{3+}$ and $\mathrm{Sr}^{2+}$ one would indeed expect 0.50 carriers per unit cell and a field-induced increase of the carrier density to explain the CMR effect could be ruled out by these data. Interestingly, Hall studies on $\mathrm{La}_{0.67} \mathrm{Ca}_{0.33} \mathrm{MnO}_{3}$ films by Jakob et al. pointed to $n \approx 1.3$ hole-type carriers per formula unit, which is considerably more than the 0.33 holes/f.u. expected from the $\mathrm{La}^{3+} / \mathrm{Ca}^{2+}$ ratio [111]. This is a strong indication for a compensation effect in the sense of Eq. (4): Using appropriate assumptions for the Fermi velocities and scattering times, the unphysically high, apparent carrier density could be delineated to a superposition of 0.55 holes and 0.5 electrons per formula unit. Such a partly compensated Fermi surface was also predicted by band-structure calculations on this compound [114]. Besides of hole-doped manganites, there are also manganites with electrons as majority charge carriers such as $\mathrm{La}_{0.33} \mathrm{Ca}_{0.67} \mathrm{MnO}_{3}$ [115] and $\mathrm{Sm}_{0.2} \mathrm{Ca}_{0.8} \mathrm{MnO}_{3}$, showing complex metamagnetic states [116]. In the 'bordering' case of half-doped $\mathrm{La}_{0.50} \mathrm{Ca}_{0.50} \mathrm{MnO}_{3}$, a transition from mainly electron- to mainly hole-type carriers was observed for temperatures below $100 \mathrm{~K}$ and fields above 10 Tesla [117].

To conclude, we mention that there is also proportionality between the anomalous Hall coefficient $R_{\mathrm{A}}$ and the longitudinal resistivity $\rho_{x x}$ expressed in the power law of Eq. (5) $[112,118]$. The basic idea is that asymmetric scattering at local magnetic moments causes not only the anomalous
Hall contribution but contributes also strongly to longitudinal resistance:

$$
R_{A}(T) \propto\left(\rho_{x x}(T)\right)^{\beta}
$$

The exponent $\beta$ should be equal to one for pure skew scattering and $\beta=2$ is expected when only the side-jump mechanism is active. The anomalous contribution at a given temperature $T$ is obtained from the linear extrapolation of the Hall voltage in high magnetic fields back to zero field. Experimental values range from $\beta \approx 1.56$ to 1.74 , indicating that both magnetic scattering mechanisms are present in CMR manganites [111, 113]. For an in-depth discussion on all phenomena introduced in this section and many more topics we refer the book 'Colossal magneto-resistive oxides' edited by Y. Tokura [119] and topical review articles [120-122].

\section{Superconducting perovskites}

5.1 Structure and critical temperature of high- $T_{c}$ cuprates The first perovskite material for which superconductivity was reported, already in 1975, is the cubic $\mathrm{BaPb}_{1-x} \mathrm{Bi}_{x} \mathrm{O}_{3}$ [123]. The superconducting phase appeared for the substitution ratio $x=0.05-0.3$, the latter corresponding to the highest critical temperature $T_{c}=13 \mathrm{~K}$ as confirmed by resistance- and magnetization measurements. Related bismuthates with an A-site substitution such as $\mathrm{Ba}_{1-x} \mathrm{~K}_{x} \mathrm{BiO}_{3}$ can reach $T_{\mathrm{c}}$ up to ca. $32 \mathrm{~K}$ for $x=0.4$ [124]. The topic started flourishing in 1986 when J. G. Bednorz and K. A. Müller discovered superconductivity with $T_{\mathrm{c}}=30 \mathrm{~K}$ in $\mathrm{La}_{1.85} \mathrm{Ca}_{0.15} \mathrm{CuO}_{4}$, a layered Ruddlesden-Popper compound with $n=1$ [9]. Only 1 year later, in 1987, Wu et al. developed $\mathrm{YBa}_{2} \mathrm{Cu}_{3} \mathrm{O}_{7-\delta}$ (YBCO), the first compound reaching the superconducting state just by cooling in liquid nitrogen (LN) at $77 \mathrm{~K}$, see Fig. 9 [125]. By careful engineering of the oxygen deficiency $\delta$, critical temperatures

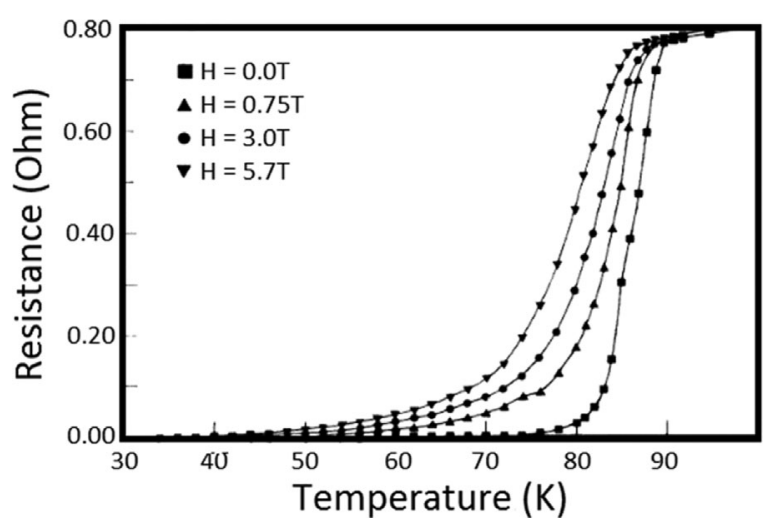

Figure 9 Temperature dependence of the resistance of ceramic $\mathrm{YBa}_{2} \mathrm{Cu}_{3} \mathrm{O}_{7-\delta}$, the first compound with Tc above liquid nitrogen temperature. The superconducting transition shows a characteristic broadening in external magnetic fields. Figure reprinted from Ref. [125] with permission. Copyright (2017) by the American Physical Society. 
up to $93 \mathrm{~K}$ can be reached, making YBCO probably one of the 'most studied materials' on earth besides iron and silicon. Looking into the composition of these hightemperature superconductors, it is immediately clear that copper is present as a mixture of $\mathrm{Cu}^{2+}$ and $\mathrm{Cu}^{3+}$, being the basis for electrical conductivity. Also a common feature are $\mathrm{CuO}_{2}$ planes as transport channels for current and an increasing number of $\mathrm{CuO}$ planes per unit cell goes tentatively along with increasing $T_{\mathrm{c}}$, see Table 2 . This holds at least for the series $\mathrm{Bi}_{2} \mathrm{Sr}_{2} \mathrm{Ca}_{\mathrm{m}-1} \mathrm{Cu}_{\mathrm{m}} \mathrm{O}_{2 \mathrm{~m}+4+\delta}$ with $m=1$, 2, 3; also higher $\mathrm{m}$ values are possible, but phase-pure specimens with, $m=4$ or 5 have so far not been reported [126]. The crystal structure of YBCO, as a prototype for high- $T_{\mathrm{c}}$ cuprates is depicted in Fig. 10.

\subsection{Critical current density and critical magnetic} fields One of the driving forces for the tremendous research efforts put into HTSC materials was the promise of loss-free current transport, preferably over longer distances in the power grid, just by cooling to $\mathrm{LN}$ temperature. The relevant figure of merit is the three-dimensional critical surface $\left(T_{\mathrm{c}}, B_{\mathrm{c}}\right.$ and $j_{\mathrm{c}}$ ), where $j_{\mathrm{c}}$ denotes the critical current density and $B_{\mathrm{c}}$ the critical magnetic field. In type II superconductors, as HTSC are, the magnetic flux penetrates the superconductor as individual flux lines or 'vortices' $\Phi_{0}$ (flux quantum $\Phi_{0}=2.0710^{-15} \mathrm{Tm}^{2}$ ) in order to maximize the interface between normal-conducting and superconducting areas. Two critical fields are defined, that is, the first, lower critical field $\left(B_{\mathrm{c} 1}\right)$ at which the first flux line enters the superconducting sample, and the second, upper critical field $\left(B_{\mathrm{c} 2}\right)$ at which the superconductivity of the sample is completely suppressed. Superconductivity can rarely be seen as a completely homogeneous state but needs to be, for practical use, dominant in most areas of the material. Even more, the superconducting transition in type II superconductors is characterized by an onset $T_{\mathrm{c}}{ }^{\text {on }}$ and offset $T_{\mathrm{c}}$ off value, respectively where the transition starts when cooling

Table 2 Overview of critical temperatures $T_{\mathrm{c}}$ of selected hightemperature superconducting materials and reference compounds.

\begin{tabular}{lll}
\hline compound & critical temperature & reference \\
\hline $\mathrm{BaBi}_{0.25} \mathrm{~Pb}_{0.75} \mathrm{O}_{3}$ & $13 \mathrm{~K}$ & {$[123]$} \\
$\mathrm{Nb}_{3} \mathrm{Ge}_{\mathrm{La}_{1.85} \mathrm{Ca}_{0.15} \mathrm{CuO}_{4}}^{23 \mathrm{~K}}$ & {$[127]$} \\
$\mathrm{YBa}_{2} \mathrm{Cu}_{3} \mathrm{O}_{7-\delta}$ & $30 \mathrm{~K}$ & {$[9]$} \\
$\mathrm{Bi}_{2} \mathrm{Sr}_{2} \mathrm{CuO}_{6+\delta}$ & $93 \mathrm{~K}$ & {$[125]$} \\
$\mathrm{Bi}_{2} \mathrm{Sr}_{2} \mathrm{CaCu}_{2} \mathrm{O}_{8+\delta}$ & $10 \mathrm{~K}^{\mathrm{a}}$ & {$[126]$} \\
$\mathrm{Bi}_{2} \mathrm{Sr}_{2} \mathrm{Ca}_{2} \mathrm{Cu}_{3} \mathrm{O}_{10+\delta}$ & $85-92 \mathrm{~K}$ & {$[126]$} \\
$\mathrm{Tl}_{2} \mathrm{Ba}_{2} \mathrm{Ca}_{2} \mathrm{Cu}_{3} \mathrm{O}_{10+\delta}$ & $110 \mathrm{~K}$ & {$[126]$} \\
$\mathrm{HgBa}_{2} \mathrm{Ca}_{2} \mathrm{Cu}_{3} \mathrm{O}_{8+\delta}$ & $125 \mathrm{~K}$ & {$[128]$} \\
$\mathrm{H}_{2} \mathrm{~S}$ & $135 \mathrm{~K}^{\mathrm{b}}, \approx 150 \mathrm{~K}^{\mathrm{c}}$ & {$[129]$} \\
\hline
\end{tabular}

${ }^{\text {a }}$ Possibly due to intercalated $\mathrm{Bi}-2212$ layers, single $\mathrm{CuO}_{2}$ layers are assumed not to support superconductivity.

${ }^{\mathrm{b}}$ Under ambient pressure.

${ }^{c}$ Under $150 \mathrm{kbar}$ pressure. Note that critical temperatures are affected by the oxygen excess or deficit $\delta$.
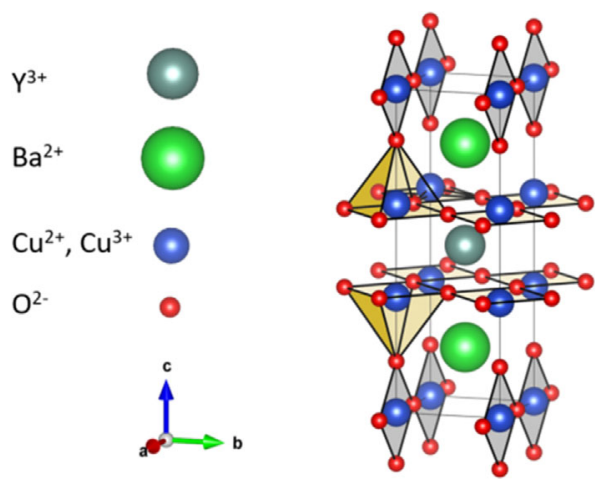

Figure 10 Unit cell of the cuprate superconductor $\mathrm{YBa}_{2} \mathrm{Cu}_{3} \mathrm{O}_{7-\delta}$ : The $\mathrm{CuO}_{6}$ octahedra of the cubic perovskite structure are split into two $\mathrm{CuO}_{5}$ pyramids separated by a $\mathrm{Y}^{3+}$ sheet and the superconducting current is confined to the yellow-shaded $\mathrm{CuO}_{2}$ planes. The arrangement of the $\mathrm{CuO}$ chains in the top- and bottom layer of the unit cell causes a weak orthorhombic distortion $(a=3.82 \AA$, $b=3.89 \AA, c=11.68 \AA$ ) which is responsible for twinning-type defects in thin films and single crystals.

down, and where the transition is completely finished. The width of the transition is usually a criterion for the 'purity' and homogeneity of the superconductor. The classical low temperature superconductors of type I, can have very sharp transitions, $\Delta T_{\mathrm{c}}<0.1 \mathrm{~K}$, but that is not observed in HTSC, where transition widths from $1-10 \mathrm{~K}$ are rather standard, compare Fig. 9.

The third important limit for the superconducting state is the critical current density $j_{\mathrm{c}}$ for which we refer to Table 3. The way how current flows in hard type II

Table 3 Critical current density $j_{\mathrm{c}}$ of important high- $T_{\mathrm{c}}$ sample types in zero magnetic field (self-induced field SF) and in a magnetic field $\mathrm{B}$ oriented parallel to the crystallographic c-axis ${ }^{\mathrm{a}}$.

\begin{tabular}{|c|c|c|c|}
\hline sample type & $j_{\mathrm{c}}\left(\mathrm{A} \mathrm{cm}^{-2}\right)$ & $T(\mathrm{~K}), B(\mathrm{~T})$ & reference \\
\hline \multicolumn{4}{|l|}{ theoretical limit ${ }^{\mathrm{b}}$} \\
\hline $\begin{array}{l}\mathrm{YBa}_{2} \mathrm{Cu}_{3} \mathrm{O}_{7-\delta} \\
\text { single crystals }\end{array}$ & $3.0 \times 10^{7}$ & $0 \mathrm{~K}, \mathrm{SF}$ & [133] \\
\hline $\begin{array}{l}\mathrm{Bi}_{2} \mathrm{Sr}_{2} \mathrm{CaCu}_{2} \mathrm{O}_{8+\delta} \\
\text { epitaxial thin films }\end{array}$ & $2 \times 10^{6}$ & $20 \mathrm{~K}, \mathrm{SF}$ & {$[134]^{\mathrm{c}}$} \\
\hline $\mathrm{YBa}_{2} \mathrm{Cu}_{3} \mathrm{O}_{7-\delta}$ & $3.5 \times 10^{6}$ & $77 \mathrm{~K}, \mathrm{SF}$ & {$[135]^{\mathrm{d}}$} \\
\hline $\mathrm{Bi}_{2} \mathrm{Sr}_{2} \mathrm{CaCu}_{2} \mathrm{O}_{8+\delta}$ & $\begin{array}{r}4 \times 10^{5} \\
<10^{2}\end{array}$ & $\begin{array}{l}77 \mathrm{~K}, \mathrm{SF} \\
77 \mathrm{~K}, 1 \mathrm{~T}\end{array}$ & [136] \\
\hline \multicolumn{4}{|l|}{ multifilament cables } \\
\hline $\mathrm{Bi}_{2} \mathrm{Sr}_{2} \mathrm{CaCu}_{2} \mathrm{O}_{8+\delta}$ & $\begin{array}{l}6.0 \times 10^{5} \\
2.0 \times 10^{5}\end{array}$ & $\begin{array}{l}4.2 \mathrm{~K}, \mathrm{SF} \\
4.2 \mathrm{~K}, 30 \mathrm{~T}\end{array}$ & [137] \\
\hline \multicolumn{4}{|l|}{ coated metal tapes } \\
\hline $\mathrm{REBa}_{2} \mathrm{Cu}_{3} \mathrm{O}_{7-\delta}$ & $\begin{array}{r}10-100 \times 10^{3} \\
5-35 \times 10^{3}\end{array}$ & $\begin{array}{r}4.2 \mathrm{~K}, 19 \mathrm{~T} \\
77 \mathrm{~K}, \mathrm{SF}\end{array}$ & {$[138]^{e}$} \\
\hline
\end{tabular}

${ }^{a}$ Due to the layered, anisotropic structure of HTSC materials, the critical current density obtained with the B field parallel to the superconducting $\mathrm{CuO}$ planes comes close to the $\mathrm{ZF}$ value [139].

${ }^{\mathrm{b}}$ Based on Ginzburg-Landau theory.

${ }^{\mathrm{C}}$ Laminar structure induced.

${ }^{\mathrm{d}}$ After irradiation with $3 \mathrm{MeV}$ Au ions.

${ }^{\mathrm{e} C}$ Comparison of six commercial manufacturers. 
superconductors is rather complex: There are several contributions to the total current, including the applied current, screening currents trying to block external magnetic fields, and the currents that generate the vortices. All these currents are determined by the geometry of the superconductor and phenomena as current crowding can easily occur. This is the reason why the critical current density is written as a small letter symbol $j_{\mathrm{c}}$, denoting the local nature of this parameter. The important criterion for superconductivity is that the force of a current, exerted on a flux line in a sample, does not exceed the pinning force of that flux line. If this happens, a flux line would move which will destroy the Cooper pairs locally, leading to Ohmic losses and resistivity in the sample [131]. For practical applications, this flux pinning is an essential mechanism, making the superconductor 'hard'. As flux lines in a superconductor generate normalconducting areas, a certain amount of condensation energy is lost. However, if there are predefined, nonsuperconducting areas present in the sample (such as impurities and grain boundaries), less condensation energy is sacrificed when a flux line is fixated by such a pinning center. Therefore, superconductors are deliberately polluted with defects, acting as pinning centers, which allow increasing $j_{\mathrm{c}}$.

Since $B$ and $j$ are intrinsically related to each other as described by the Maxwell equations, both current and field have a destructive effect on superconductivity. In an external magnetic field, with a strength between the lower and the upper critical field, $j_{\mathrm{c}}$ drops rapidly with increasing $B$ field, due to dissipative movement of magnetic flux lines due to the loss of pinning. This complex relation can be described via a generalized phenomenological formula in Eq. (6) [132]:

$$
j_{c}(T, B)=j_{c}(T) /\left(1+B / B_{0}\right)^{\beta}
$$

Here, $j_{\mathrm{c}}(T)$ is the critical current density in the absence of an external magnetic field, $B_{0}$ is a scaling parameter, and the exponent $\beta(0.5<\beta<1.5)$ depends on the flux-pinning mechanism that is active. In case of multifilament $\mathrm{Bi}_{2} \mathrm{Sr}_{2} \mathrm{CaCu}_{2} \mathrm{O}_{8+\delta}$ cables, taking $j_{\mathrm{c}}(T=4.2 \mathrm{~K})=6.0 \times 10^{5} \mathrm{~A}$ $\mathrm{cm}^{-2}, \quad B_{0}=15 \mathrm{~T}$ and $\beta=1$, we obtain $j_{\mathrm{c}}(T=4.2 \mathrm{~K}$, $B=30 \mathrm{~T})=2.0 \cdot 10^{5} \mathrm{~A} \mathrm{~cm}^{-2}$ in nice agreement with experimental data, see Table 3 .

Due to the lack of pinning, virtually defect-free crystals are not the sample-type of choice. Thin-film samples, even epitaxial ones, are much better suited for obtaining high $j_{\mathrm{c}}$ values due to their intrinsic defects, including a certain density of grain boundaries and several types of dislocations such as growth spirals [140]. In addition, artificial, pointlike defects have been engineered including the examples of $\mathrm{Zn}$ - and $\mathrm{Ni}$ substitution on the copper sites in the $\mathrm{CuO}_{2}$ planes [141, 142], columnar defects by heavy-ion irradiation [143], impurity (green) phase incorporation [144], and $\mathrm{BaZrO}_{3}$ inclusions [145]. The critical current densities achieved with epitaxial films are surprisingly high, up to the order of $10^{8} \mathrm{~A} \mathrm{~cm}^{-2}$, but this is more an advantage for chiplike devices and does not solve the need for long-distance low-loss current transport. However, it did point out to the main preconditions for high current behaviour, that is, epitaxial growth and pinning.

5.3 Cuprate-based power conductors The development of HTSC-based power conductors was initially seriously hampered by the brittleness, granularity and weak-link behaviour of these materials, but progress was made along two competing tracks: Classically, powder-intube (PIT) is the first candidate technique when trying to make wires from brittle materials. The second promising concept employs coated tapes, offering the advantage that they can be used to achieve epitaxial growth, which is, as learned from thin films, a great advantage. Such coated tapes are wrapped around a central support (usually carrying $\mathrm{LN}$ ) and form rather thick 'wires' in this way.

For powder-in-tube, $\mathrm{Bi}_{2} \mathrm{Sr}_{2} \mathrm{CaCuO}_{8+\delta}$ powders are encapsulated in silver sheaths and then compacted and sintered by hot-rolling techniques. By repetitive folding and hot-rolling, multifilament wires are obtained as shown in Fig. 11. The silver matrix can carry the current for temperatures above $T_{\mathrm{c}}$ (during quench for instance) and the small diameter $(15 \mu \mathrm{m})$ of the 666 individual HTSC filaments allows for bending radii down to a couple of centimetres [137]. This way, critical current densities up to $j_{\mathrm{c}}(T=4.2 \mathrm{~K}, B=20 \mathrm{~T})=2.5 \cdot 10^{5} \mathrm{~A} \mathrm{~cm}^{-2}$ are documented for $30 \mathrm{~m}$ long cables wound as a coil (and reannealed under high oxygen pressure). For comparison, the technically allowed current through a copper wire with $1 \mathrm{~mm}^{2}$ cross-section area in household electrics is $19 \mathrm{~A}$, corresponding to $2500 \mathrm{~A} \mathrm{~cm}^{-2}$ or two orders of magnitude less than what is achieved with PIT HTSC wires [146]. Evidently, permanent cooling by LN or liquid helium $(\mathrm{LHe})$ is a necessity, but in stationary applications such as magnetic field coils the solution is technically easy due to

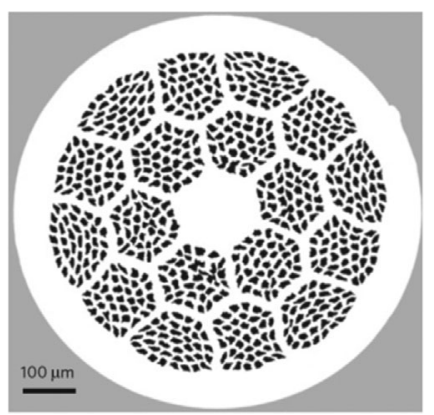

Figure 11 Optical micrograph of a cross section of a multifilament, high-current cable based on $\mathrm{Bi}_{2} \mathrm{Sr}_{2} \mathrm{CaCuO}_{8+\delta}$ filaments (dark colour) embedded in a supporting silver matrix. The wire has $0.8 \mathrm{~mm}$ diameter and the critical current density jc corresponds to $2.5 \times 105 \mathrm{~A} \mathrm{~cm}^{-2}$ at $4.2 \mathrm{~K}$ in a 20 Tesla field. Reprinted by permission from Macmillan Publishers Ltd: Nature Materials, Ref. [137], copyright 2014. 
mature superinsulation methods and also efficient cryocoolers are industrially available to this end.

More recently, attention has shifted towards the coatedtapes method in order to enable real power applications using HTSC. The structure of a typical second-generation coated tape (2G) is shown in Fig. 12. The carrier tape can be made of alloys such as Hastelloy, NiCroFer, and $\mathrm{Ni}$ alloys, while typical buffer materials are oxides including $\mathrm{MgO}$, $\mathrm{ZrO}, \mathrm{Y}_{2} \mathrm{O}_{3}$, STO and yttria-stabilized zirconia. For the choice of the HTSC material the $\mathrm{REBa}_{2} \mathrm{Cu}_{3} \mathrm{O}_{7}$ family is appropriate with $\mathrm{RE}$ denoting rare-earth cations. The quench- and chemical protection layer (shunt) can consist of silver, gold or copper. Epitaxy in the HTSC layer is obtained by using rolling-assisted, bi-axially textured substrates as tape, and via the buffer layers which can be ion beam assisted deposited or inclined substrate deposited (under an angle). Deposition of the YBCO layer is accomplished via metal-organic inkjet printing, followed by thermal pyrolytic treatments [138]. In 2016, impressive values for $j_{\mathrm{c}}$ of up to $3.5 \times 10^{6} \mathrm{~A} \mathrm{~cm}^{-2}$ have been reached in the laboratories of some of the major industrial players.

5.4 High-precision magnetometry The most sensitive magnetometers till date are based on superconducting quantum-interference devices (SQUIDS). High- $\mathrm{T}_{\mathrm{c}}$ cuprates play an enabling role for mobile SQUID applications, needed in materials testing and medical studies, since cooling with $\mathrm{LN}$ is considerably easier to handle than LHe cooling. Figure 13 shows the basic device, consisting of a ring with a few hundred micrometer diameter and electrical contact leads, both etched lithographically from a thin HTSC film on an insulating substrate. The key elements are two 'weak links' (Josephson junctions, consisting of non-superconducting material) across which superconducting Cooper pairs can pass by tunnelling. The magnetic flux through a superconducting ring with cross-section area $A$ is given by $\Phi=B \times A$, which is quantized in units of the elemental flux quantum $\Phi_{0}=2.07 \times 10^{-15} \mathrm{~T} \mathrm{~m}^{2}$. When sending a fixed current $I_{\text {bias }}$ through the loop, each additional flux quantum $\Phi_{0}$ passing the ring will cause a well-defined maximum in the measured voltage and, by counting the number of voltage peaks, one can recalculate the strength of the local magnetic field with high accuracy.

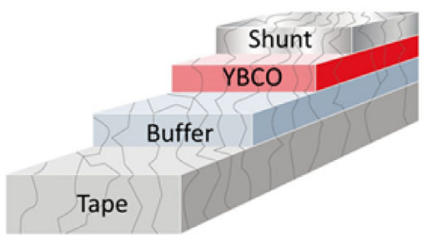

Figure 12 Schematics of a coated conductor, with the different layers of interest. The tape is essentially a strong elastic metallic carrier, the (usually insulating) buffer should allow epitaxial growth of the HTSC $\left(\mathrm{YBa}_{2} \mathrm{Cu}_{3} \mathrm{O}_{7}\right)$ and the shunt layer should protect against quenching.
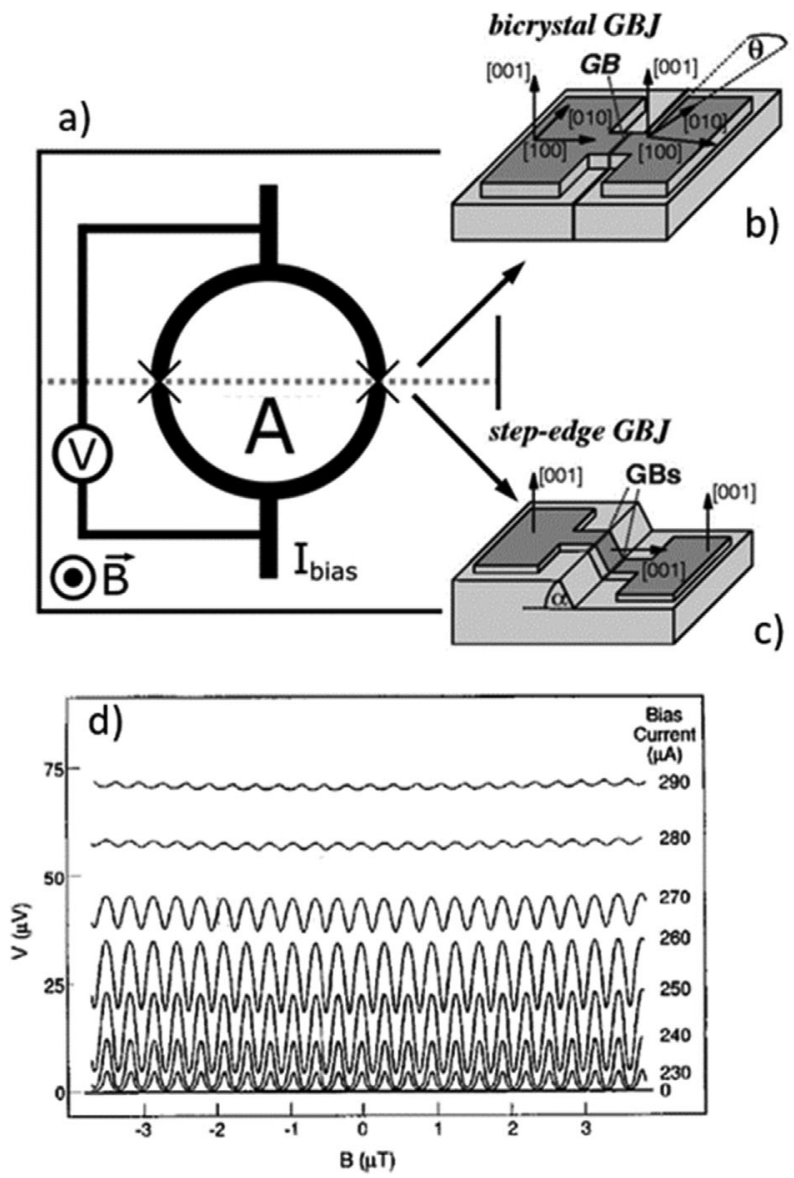

Figure 13 a) Schematic illustration of a d.c. SQUID with two Josephson junctions indicated by ' $x$ '. These junctions are obtained by depositing an YBCO thin film (dark colour) on a pre-engineered substrate containing a bicrystal grain boundary (b) or a step-edge boundary (c) along the dotted line. Magnetic flux through the loop causes periodic voltage oscillations $(\mathrm{V})$, depending in magnitude on the current Ibias, see panel (d) for a bicrystal SQUID at $77 \mathrm{~K}$. Figures b)-d) are reprinted with permission from Ref. [149] Copyright (2017) by the American Physical Society.

Fabricating weak links with controlled and reproducible properties is a considerable challenge and the developed solutions are beautiful examples of surface- and interface engineering. Two concepts provide the best results: Grainboundary junctions can be prepared by patterning the SQUID structure over a bicrystal substrate in which the HTSC layers on both sides of the junction differ in the orientation of the $a$ - and $b$ axes as illustrated in Fig. 13b). To make such bicrystals, for example, standard SrTiO substrates are sintered together in a way that their in-plane orientation is misaligned with respect to each other under angles of typically $24^{\circ}$ or $36.8^{\circ}$ [147, 148]. The second alternative is a step-edge junction shown in Fig. 13c): Here, part of the substrate is thinned down by ion-beam milling using a shadow mask and typical edge heights are in the order of $100 \mathrm{~nm}$ (similar to the thickness of the YBCO film) with ramp angles of $65^{\circ}$, see Ref. [150, 151], Strictly 
speaking, one step edge junction contains two weak links in series, making this arrangement tentatively more susceptible for noise.

An overview on SQUID technology based on high- $T_{c}$ cuprates can be found in a review article by Koelle and coworkers [149]. There are also more recent articles on mobile SQUID applications in unshielded environments, including magnetocardiography on patients [152], nuclear magneticresonance spectroscopy [153], and non-destructive materials testing at the microscopic scale [154].

5.5 Superconductivity at perovskite-perovskite heterointerfaces In order to elucidate the relevance of charge carrying, separated layers for high- $\mathrm{T}_{\mathrm{c}}$ superconductivity, Ohtomo and Hwang engineered in 2004 synthetic interfaces between $\mathrm{LaAlO}_{3}$ and $\mathrm{SrTiO}_{3}$ [155]. Both compounds are wide-bandgap insulators and to understand the properties of the interface we can imagine $\mathrm{SrTiO}_{3}$ as an alternating stack of neutral $(\mathrm{SrO})^{0}$ - and $\left(\mathrm{TiO}_{2}\right)^{0}$ sheets. $\mathrm{LaAlO}_{3}$ is build up from charged $(\mathrm{LaO})^{+}$- and $\left(\mathrm{AlO}_{2}\right)^{-}$ layers and two different types of epitaxial interfaces with $\mathrm{SrTiO}_{3}$ are possible: The $\left(\mathrm{AlO}_{2}\right)^{-} /(\mathrm{SrO})^{0}$ interface is expected to show $1 / 2$ hole-type carrier per two-dimensional unit cell, but specimens turned out to be insulating. The $(\mathrm{LaO})^{+} /\left(\mathrm{TiO}_{2}\right)^{0}$ interface, with $1 / 2$ electron-type carrier per u.c., displayed electrical conductivity with exceedingly higher carrier mobility up to $10^{4} \mathrm{~cm}^{2} \mathrm{~V}^{-1} \mathrm{~s}^{-1}$ for $T<10 \mathrm{~K}$. The existence of quantum oscillations in the Hall voltage proved directly that a two-dimensional electron gas (2DEG) was present at the interface of two insulating materials.

By applying gate voltages between the 2DEG and a backside contact, separated from the 2DEG by the insulating $\mathrm{SrTiO}_{3}$, Caviglia et al. managed to tune the carrier concentration of the electron gas in wide ranges and to shift the system between a superconducting- and an insulating ground state [156]. The critical temperature is in the order of $250 \mathrm{mK}$ for zero bias and decreases for both, positive and negative, gate voltages up to $300 \mathrm{~V}$ [157]. This is unexpected in the sense that a high carrier density should increase the $T_{c}$ value. Another unexpected feature came from tunnelling spectroscopy: Richter and co-workers found in the differential conductance $\mathrm{d} I / \mathrm{d} V$ a clear pseudogap in the electronic density of states with signatures corresponding to the energy scale of phonon excitations in $\mathrm{SrTiO}_{3}$. At first glance, this agrees well with the classical BCS theory of superconductivity, predicting that phonons mediate the coupling of independent electrons to bosonic Cooper pairs [158]. However, the pseudogap remained visible for temperature- and gate-voltage values in which the 2DEG was far outside its superconducting state, thus contradicting the BCS picture. It is too early for definite conclusions regarding the coupling mechanism in superconductivity at interfaces, but pseudogap features in the normal state have also been reported for epitaxial $\mathrm{La}_{2-x} \mathrm{Sr}_{x} \mathrm{CuO}_{4}$ thin films [65]. More information on the nano-structural aspects of $\mathrm{SrTiO}_{3} / \mathrm{LaAlO}_{3}$ interfaces, as evidenced by transmission-electron microscopy (TEM) and electron-energy loss spectroscopy (EELS) can be found in an article by Verbeeck and co-workers [79].

For a complete introduction into superconductivity, the underlying theories, materials aspects, and the existing and emerging applications, we refer the reader to the recent textbook 'Superconductivity: An Introduction' by R. Kleiner, W. Buckel and R. Huebener [127].

\section{From dielectric to multiferroic perovskites 6.1 Spontaneous polarization in ferroelectrics}

The fact that perovskites exhibit high relative dielectric constants $\varepsilon_{\mathrm{r}}$ is well known with values up to $\varepsilon_{\mathrm{r}} \approx 7000$ for $\mathrm{BaTiO}_{3}$ ceramics in a narrow temperature window around the tetragonal-to-cubic phase transition at $120^{\circ} \mathrm{C}[159,160]$. At room temperature, $\varepsilon_{\mathrm{r}}$ is still in the order of 1500 , making the material an ideal dielectric for high-performance capacitors. Perovskites such as $\mathrm{SrZrO}_{3}$ and $\mathrm{SrHfO}_{3}$ are also under consideration as so-called "high- $\kappa$ dielectric gate insulators' for future nanoelectronic logic elements $[161,162]$. As in all dielectrics, external electric fields cause a shift in the electron distribution around the ions, which is here strongly corroborated by a shift of anions and cations with respect to each other, thus causing a macroscopic polarization $P$ (dipole moment/volume) of the sample.

In certain perovskites, termed 'ferroelectrics' (FE), such polarization occurs spontaneously at and below the Curie temperature $T_{\mathrm{C}}$, which is here unrelated to the Curie temperature indicating ferromagnetic ordering. To avoid confusion, the FE-ordering temperature can also be abbreviated as $T_{\mathrm{FE}}$. Spontaneous polarization always goes along with deviations from the ideal cubic structure, which cannot sustain a permanent electrical dipole moment for symmetry reasons. This can be visualized as a shift of $\mathrm{Ti}^{4+}$ out of the center position of the $\mathrm{Ti}^{4+} \mathrm{O}_{6}{ }^{2-}$ octahedrons towards one (or three) of the $\mathrm{O}^{2-}$ sites, which favours orbital overlap between the $2 p$ electrons of this $\mathrm{O}^{2-}$ and the empty $3 d$ levels of $\mathrm{Ti}^{4+}$ [163]. Herewith, the deformation and polarization are stabilized at the unit-cell scale by a lowering of the electrons' kinetic energy through formation of a bonding molecule orbital between $\mathrm{Ti}^{4+}$ and $\mathrm{O}^{2-}$. For Ca-, $\mathrm{Sr}-, \mathrm{Ba}-$ and $\mathrm{Pb}$ titanates, the dielectric constant follows a temperature dependence according to Eq. (7) [10]:

$$
\varepsilon_{r}(T)=\varepsilon_{l}+\frac{C}{T-T_{C}}
$$

The Curie constant $C$ and the Curie temperature increase systematically with the mass (atomic number) of the $B$-site cation and $\varepsilon_{1} \approx 50$ is the high-temperature limit of $\varepsilon_{\mathrm{r}}$. Eq. (7) is valid in the paraelectric regime, that is, above $T_{\mathrm{C}}(=763 \mathrm{~K}$ for the example of $\mathrm{PbTiO}_{3}$ ) and reproduces correctly the divergence of $\varepsilon_{\mathrm{r}}$ and transition to the ferroelectric regime upon cooling below the Curie point. Selected ferroelectrics including $\mathrm{LiNbO}_{3}, \mathrm{LiTaO}_{3}$, and $\mathrm{BaTiO}_{3}$ are also described as 'pyroelectric' or 'photo-pyroelectric' materials: Here, the spontaneous polarization $P$ and polarization-induced voltage depend sensitively on temperature and illumination 
conditions with ultrashort response times. Hence, singlecrystalline (photo-) pyroelectric detectors play an important role in thermometric methods for precision measurements on the thermal conductivity and heat capacity of solids and liquids $[164,165]$.

6.2 Piezoelectric materials A technically most important, mixed perovskite is the piezoelectric leadzirconate titanate $\mathrm{PZT}$ with the composition $\mathrm{Pb}\left(\mathrm{Zr}_{x} \mathrm{Ti}_{1-x}\right)$ $\mathrm{O}_{3}(x \approx 0.52)$. We can consider PZT as a solid solution of ferroelectric $\mathrm{PbTiO}_{3}$ (tetragonal) and antiferroelectric, rhombohedral $\mathrm{PbZrO}_{3}$, meaning that the polarization in the unit cells of the latter shows an alternating orientation [166]. Mixed crystals or ceramics are approximately tetragonal with the $\mathrm{Zr}^{4+}$ and $\mathrm{Ti}^{4+}$ ions shifted along the $c$ axis out of the center of the unit cells, thus causing a dipole moment in each u.c.. Exposing the material at temperatures above $T_{\mathrm{C}}$ to strong electrical fields (poling procedure), a uniform, macroscopic polarization and elongation are obtained. By applying later electrical fields, the specimens can be elongated or contracted with high precision and, vice versa, mechanical deformations will alter the polarization voltage, being together the direct- and the indirect piezoelectric effect. Applications of piezoelectric compounds are countless and include ultrasound transducers, analytical microbalances, actuators such as for the precision positioning of cantilevers in scanningtunnelling- and atomic force microscopy (STM/AFM), and energy harvesting systems, see Refs. [96, 167, 168] for an overview.

Although PZT is still the most widely used piezoelectric material due to its outstanding performance and commercial availability, there is an active and ongoing search for lead-free perovskites as potential replacements $[166,169,170]$. On the side of novel experimental methods, we mention that it is now also possible to map the ferro- and piezoelectric properties of complex materials with high spatial resolution down to $1 \mu \mathrm{m}$ and less as summarized in a review by Batagiannis and co-workers [171]. This is also the typical lateral scale of microengineered sensors, actuators, and memory-storage devices, giving a boost to new synthesis routes for nanostructured piezo- and ferroelectric perovskite materials discussed in Ref. [172].

6.3 Multiferroic perovskites are another interesting class of materials that combine ferroelectric and ferromagnetic properties. Although the combination of both effects is far from trivial, multiferroics should allow to change the magnetization state of a specimen by electric fields and, vice versa, to control its electrical polarization by magnetic fields, both with potential applications in memory devices. This bidirectional phenomenon is known as magnetoelectric (ME) effect and a detailed overview can be found in Ref. [173]. As pointed out in a review by Khomskii, there are numerous perovskites showing either magnetic- or ferroelectric ordering while both phenomena seem to exclude each other mutually, see Ref. [163] and references therein. In most FE perovskites, the B-site cation has an empty $3 \mathrm{~d}$ shell, leading to the covalent bond with a surrounding $\mathrm{O}^{2-}$ ion while $\mathrm{FM}$ perovskites have partially filled $3 \mathrm{~d}$ orbitals at the B-site that can only form antibonding molecule orbitals with $\mathrm{O}^{2-}$. Furthermore, Hund's-rule coupling would result in an additional increase of the total energy per u.c. upon a hypothetical shift of the B-site cation within the oxygen octahedron.

Nevertheless, there are FE perovskites showing antiferro-magnetic (AFM) behaviour: The AFM ordering stems from the magnetic moment of the B-site cations while ferroelectricity is caused by the A-site cations, meaning that both ordering effects are widely decoupled [163]. A nice example is $\mathrm{BiFeO}_{3}$ with $T_{\mathrm{FE}}=1100 \mathrm{~K}$ and $T_{\mathrm{N}}=643 \mathrm{~K}$, being the Neèl temperature for AFM ordering, which is induced by the super-exchange mechanism (see Sect. 4.1). The ferroelectric behaviour at the A-site in case of $\mathrm{Bi}^{3+}$, and similarly $\mathrm{Pb}^{2+}$, is associated with the $6 \mathrm{~s}^{2}$ 'lone electron pair' that causes strong electrical dipole moments without participating in chemical bonding [75, 174]. A different scenario for the joint occurrence of AFM and FE takes place in $\mathrm{YMnO}_{3}$ where the electrical polarization stems from the dipole moment of $\mathrm{Y}^{3+}-\mathrm{O}^{2-}$ pairs [175]: Again, the ordering temperatures for both long-range phenomena are distinctly different. However, this compound has not a regular perovskite structure but contains fivefold coordinated $\mathrm{Mn}^{3+}$ ions centerd in trigonal biprisms cornered by $\mathrm{O}^{2-}$ ions. As a result, the FE polarization originates from geometrical constraints and not from chemical bonding between a cation and surrounding $\mathrm{O}^{2-}$ sites.

Looking for perovskites with paraelectric and at least weakly ferromagnetic properties, $\mathrm{BiCrO}_{3}[75]$ and $\mathrm{BiFeO}_{3}$ are the most intensely studied materials [176-178]. While pure $\mathrm{BiFeO}_{3}$ is a G-type antiferromagnet (each $\mathrm{Fe}^{3+}$ is surrounded by six other $\mathrm{Fe}^{3+}$ with opposite direction of their magnetic moments), a partial substitution with gadolinium at the Bi-site results in canting of the $\mathrm{Fe}^{3+}$ spins. This generates a net magnetic moment in the order of $0.1 \mu_{\mathrm{B}}$ per $\mathrm{Fe}$ site, while $5.9 \mathrm{Bohr}$ magnetons would be expected for independent $\mathrm{Fe}^{3+}$ ions. For polycrystals of $\mathrm{Bi}_{0.8} \mathrm{Gd}_{0.2} \mathrm{FeO}_{3}$, Lazenka and co-workers found magnetoelectric coefficients $\alpha$ in the order of $9 \cdot 10^{6} \mathrm{~V} \mathrm{~m}^{-1} \mathrm{~T}^{-1}$ at room temperature [177]. The $\alpha$ coefficient is the ratio between the increase of the electrical field in the specimen (in $\mathrm{Vm}^{-1}$ ) and the applied magnetic field, indicating clearly the presence of a magnetoelectric effect. The coupling between weak ferromagnetism and ferroelectricity can also be accomplished by strain engineering in $\mathrm{BiFeO}_{3}-\mathrm{BaTiO}_{3}$ multilayers prepared by pulsed laser deposition, see Sect. 3.4, 3.5: Such specimens show high ferroelectric polarization up to $70 \mu \mathrm{C} \mathrm{cm}^{-2}$, net magnetic moments of $1 \mu_{\mathrm{B}}$ per $\mathrm{Fe}^{3+}$, and magneto-electric coefficients of $\approx 2 \times 10^{7} \mathrm{~V} \mathrm{~m}^{-1} \mathrm{~T}^{-1}[78,179]$. For an overview on multiferroics in the thin-film context, we can recommend a review article by Ramesh and Spaldin, see Ref. [180]. 


\section{Perovskites in catalysis}

7.1 $\mathrm{CO}$ oxidation and $\mathrm{NO}_{x}$ reduction Already in 1976, Voorhoeve and co-workers pointed out that a variety of perovskites (cobaltites, manganites, chromites, and ruthenates) have high potential as catalysts to oxidize $\mathrm{CO}$ and to reduce $\mathrm{NO}_{\mathrm{x}}$ in automotive exhaust gases [181, 182]. Today, this is a crucial topic given the increasingly stricter exhaust regulations and the limited resources of precious metals used in mass fabricated three-way catalysts (TWC's) that are also able to convert unburnt hydrocarbons (HC's). In their recent review, Keav et al. show that, for the oxidation of propane at low temperatures $\left(227^{\circ} \mathrm{C}\right)$ the B-site cation is most important with $\mathrm{Mn}^{3+}$ and $\mathrm{Co}^{3+}$ resulting in much higher conversion rates than $\mathrm{Cr}^{3+}, \mathrm{Fe}^{3+}$ and $\mathrm{Ni}^{3+}$ [183]. The choice of A-site cations plays a minor role, except for the fact that A-site substitutions change the average valence of the B ions, thus influencing indirectly their catalytic activity. All conversion reactions involve suprafacial (surface bound) or intrafacial (lattice bound) oxygen species that are adsorbed or released in characteristic temperature regimes. Hence, the oxygen-storage capacity and $\mathrm{O}^{2-}$ mobility of the oxide are important and both factors are related to structural defects in the perovskite lattice.

The oxidation of $\mathrm{CO}$ on a perovskite is a suprafacial reaction starting with the dissociation of $\mathrm{O}_{2}$ from the gas phase into two $\mathrm{O}$ atoms that adsorb at $\mathrm{B}$-site cations of the perovskite surface. Next, $\mathrm{CO}$ adsorbs to the surface and forms unstable $\mathrm{CO}_{3}$, which decomposes finally to an adsorbed $\mathrm{O}$ atom while $\mathrm{CO}_{2}$ is released back to the gas phase. For the intermediate steps we refer to Ref. [183] and references therein, describing also the intrafacial reactions involved in the reduction of $\mathrm{NO}_{x}$ to $\mathrm{N}_{2}$. In brief, $\mathrm{NO}$ molecules adsorb at the surface containing vacancies in the oxygen lattice. There, $\mathrm{NO}$ dissociates in a way that $\mathrm{O}$ atoms fill the vacancies while $\mathrm{N}$ atoms recombine to $\mathrm{N}_{2}$ that leaves the surface. There can also be side reactions in which adsorbed $\mathrm{N}$ atoms bind with $\mathrm{NO}$ or $\mathrm{CO}$ to $\mathrm{N}_{2} \mathrm{O}$ and $\mathrm{NCO}$, respectively. Regenerating the catalytic function means that the oxygen vacancies need to be restored by $\mathrm{CO}$ from the gas phase that takes up an $\mathrm{O}$ atom from the perovskite lattice. Ideally and in a stable process, the $\mathrm{CO}$ oxidation and $\mathrm{NO}$ reduction take place at identical rates.

As a downside, perovskite catalysts undergo activity loss under ageing, especially due to sulphur residues in the exhaust gas. Moreover, their surface-to-volume ratio is inferior to classical TWC's in which precious-metal particles are finely dispersed over a honeycomb-shaped network of alumina, ceria or silicates. Also these TWC's degrade when catalyst particles merge over time to larger agglomerates with a lower active surface area and therefore an excess of these metals is employed. An interesting option is the palladium-modified perovskite $\mathrm{LaFe}_{0.57-}$ $\mathrm{Co}_{0.38} \mathrm{Pd}_{0.05} \mathrm{O}_{3}$ for which Nishihata et al. have shown that $\mathrm{Pd}$ migrates reversibly in and out of the perovskite lattice under oxidizing and reducing gas conditions [184]. Here, Pd stays catalytically active either as a B-site cation or as dispersed Pd nanoparticles with 1-3 nm diameter on top of the perovskite surface.

There are also considerable efforts to synthesize perovskite catalysts with a textured structure in order to enhance their surface-to-volume ratio. Using hydrothermal synthesis routes from precursor solutions in combination with organic or inorganic templates resulted in mesoporous $\mathrm{LaCoO}_{3}$ - and $\mathrm{LaMnO}_{3}$ specimens, three-dimensionally ordered macroporous $\mathrm{LaCo}_{x} \mathrm{Fe}_{1-x} \mathrm{O}_{3}$ networks, and hollow $\mathrm{LaMnO}_{3}$ spheres. An overview on these advanced synthesis methods, the resulting sample morphologies, and the catalytic effects at the B-site cations can be found in a review article by Zhu and co-workers from 2014, see Ref. [185]. A more straightforward technique to enlarge the active area of $\mathrm{La}_{0.9} \mathrm{Ce}_{0.1} \mathrm{CoO}_{3}$ was reported earlier by Forni and Rosetti, who dip-coated honeycomb scaffolds in mildly acidic perovskite solutions, followed by a calcination step [186]. The perovskite was found to catalyse the flameless combustion of hydrocarbons (e.g., methane) at comparatively low temperatures $\left(800^{\circ} \mathrm{C}\right)$, thus avoiding formation of $\mathrm{CO}$ and $\mathrm{NO}_{\mathrm{x}}$ as noxious by-products. Perovskites can moreover catalyse the oxidative dehydrogenation of ethane $\left(\mathrm{C}_{2} \mathrm{H}_{6}\right)$ to ethane $\left(\mathrm{C}_{2} \mathrm{H}_{4}\right)$ and halogen-substituted perovskites such as $\mathrm{La}_{1-x} \mathrm{Sr}_{x} \mathrm{FeO}_{3-\delta} \mathrm{X}_{\sigma}$ turned out to be most efficient $[187,188]$. The materials are synthesized with an oxygen deficiency $\delta$, which is replenished by fluorine or chlorine (symbol $X_{\sigma}$ ) thus underpinning the relevance of oxygen vacancies for the catalytic mechanism.

7.2 Metal-air batteries and fuel cells Perovskites play also an increasing role in research into energy storage and conversion [189]. Our first example is about rechargeable metal-air batteries, which have a high energy contents per weight and open-circuit voltages (OCV's) up to three Volt for combinations of air with alkaline- and earthalkaline metals. During discharging of the metal-air battery, the air electrode is the negative pole at which the following reaction, termed 'oxygen-reduction reaction ORR', takes place, see also Fig. 14a):

$$
2 \mathrm{H}_{2} \mathrm{O}+\mathrm{O}_{2}+4 \mathrm{e}^{-} \rightarrow 4 \mathrm{OH}^{-}
$$

For charging, the air electrode is connected to a positive potential and the reaction of Eq. (8) runs in the opposite direction from right to left, then described as 'oxygen evolution reaction OER'. There are several possibilities for the reaction at the metal electrode, depending on the $\mathrm{pH}$ value of the electrolyte inside the battery cell. For charging, a certain overvoltage is required while discharging goes along with a decrease of the output voltage as compared to the open-circuit voltage (OCV). Both unwanted effects increase with the employed current density, see Fig. 14b), due to the fact that both reactions, ORR and OER, are complex and have a slow kinetics. Here, the RuddlesdenPopper perovskite $\mathrm{LaSr}_{3} \mathrm{Fe}_{3} \mathrm{O}_{10}(n=3)$ can play a beneficial role as shown by Takeguchi and co-workers, outperforming even the noble-metal catalyst $\mathrm{RuO}_{2}-\mathrm{IrO}_{2}$ [190]. It is 

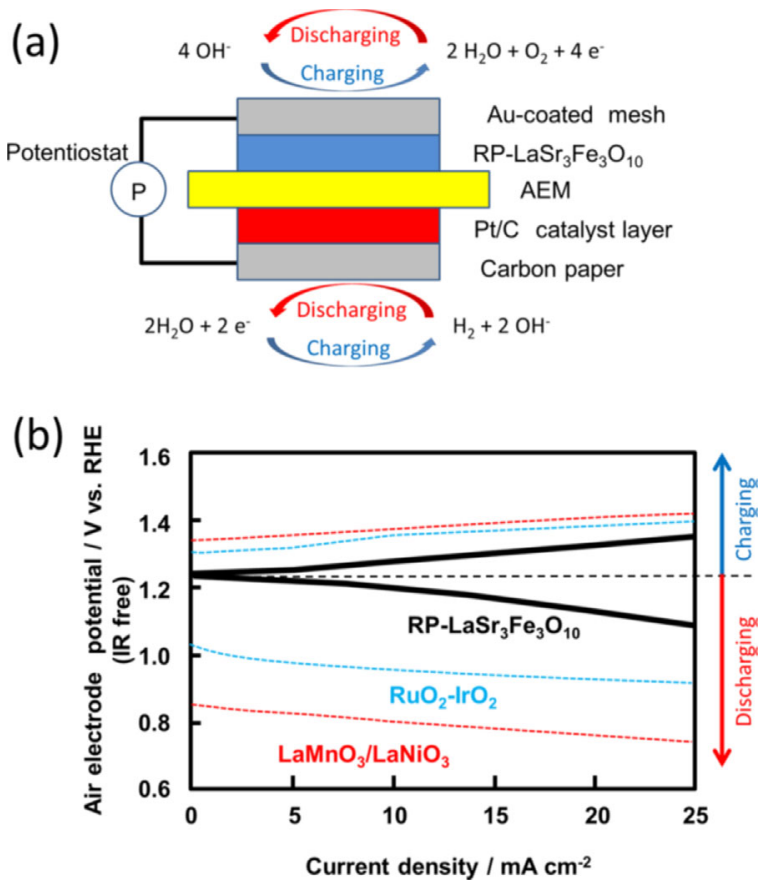

Figure 14 a) Schematic illustration of a rechargeable metal-air battery including the charging- and discharging reactions. The metal electrode $\mathrm{Pt} / \mathrm{C}$ is separated by an anion-exchange membrane (AEM, serving as solid electrolyte) from the air electrode at which the perovskite $\mathrm{LaSr}_{3} \mathrm{Fe}_{3} \mathrm{O}_{10}$ is acting as a catalyst. b) shows the airelectrode potential during charging and discharging in relation to the current density, remaining fairly stable around the OCV $\approx 1.23 \mathrm{~V}$. Figure adapted with permission from Ref. [190] Copyright (2017) American Chemical Society.

noteworthy that the perovskite catalyzes both reactions while serving also as air electrode itself and $\mathrm{OH}^{-}$ion conductor together. Similar results were reported recently for $\mathrm{La}_{0.3}\left(\mathrm{Ba}_{0.5} \mathrm{Sr}_{0.5}\right)_{0.7} \mathrm{Co}_{0.8} \mathrm{Fe}_{0.2} \mathrm{O}_{3-\delta}$ and $\mathrm{PrBa}_{0.5} \mathrm{Sr}_{0.5} \mathrm{Co}_{1.5} \mathrm{Fe}_{0.5} \mathrm{O}_{5+\delta}$, the latter in the form of nanofibers offering the additional benefit of a large surface-to-volume ratio [191, 192]. As a general trend, perovskites seem especially efficient to catalyse the OER- and ORR reactions in alkaline media, see Refs. [193-195].

The second example for energy storage and conversion are fuel cells, in which hydrogen-rich gasses such as $\mathrm{H}_{2}$ and $\mathrm{CH}_{4}$ are converted to $\mathrm{H}_{2} \mathrm{O}$ by cold combustion, thus releasing electricity and 'electrolysers', splitting water into its components according to the sum reaction of Eq. (9).

$$
2 \mathrm{H}_{2}+\mathrm{O}_{2} \leftrightarrow 2 \mathrm{H}_{2} \mathrm{O}
$$

Special advantages of fuel cells are seen in their compact size, high energy-conversion efficiency, and evidently their clean exhaust in the form of pure water. However, there are still considerable challenges in the development of electrodes (without precious-metal catalysts) that are long-term reliable and in developing electrolyte materials for which solid oxides are a promising option. In most types of fuel cells, reaction (8) takes place in a way that $\mathrm{H}_{2}$ decomposes catalytically at the anode into electrons and protons $\left(\mathrm{H}^{+}\right.$ions), the latter migrating through the electrolyte to the cathode side. Solid-oxide fuels cells (SOFC's) are different in the sense that $\mathrm{O}_{2}$ molecules are converted to $\mathrm{O}^{2-}$ ions at the cathode before they migrate through the electrolyte to the anode. Hence, electrolyte materials with a high ionic conductivity for $\mathrm{O}^{2-}$ are required, bringing perovskites with oxygen vacancies into the focus. For an overview on such SOFC's, their materials, and manufacturing techniques we refer to a review article by Menzler et al. [196]: Here, $(\mathrm{La}, \mathrm{Sr}) \mathrm{CoMn}_{3}$ and $(\mathrm{La}, \mathrm{Sr}) \mathrm{MnO}_{3}$ are introduced as catalytically active and electrically conducting cathode material while $\mathrm{La}_{0.8} \mathrm{Sr}_{0.2} \mathrm{Ga}_{0.85} \mathrm{Mg}_{0.15} \mathrm{O}_{2.825}$ is a candidate for the $\mathrm{O}^{2-}$ conductive electrolyte. Also the substituted double perovskite $\mathrm{Sr}_{2} \mathrm{Mg}_{1-x} \mathrm{Mn}_{x} \mathrm{MoO}_{6-\delta}$ was successfully employed as an anode material with special advantage of its long-term stability at elevated temperatures and resilience against sulphur residues in the fuel gas [197].

\section{Perovskites in photovoltaic applications}

8.1 Single-junction perovskite solar cells The recent rise of organometal halide perovskite solar cells also termed as hybrid organic-inorganic perovskite solar cells - starts in 2009, when methylammonium lead iodide $\left(\mathrm{CH}_{3} \mathrm{NH}_{3} \mathrm{PbI}_{3}\right)$ was introduced by Kojima et al. as sensitizer (dye) in liquid electrolyte based Dye Sensitized Solar Cells (DSSC's), reaching a Power Conversion Efficiency (PCE) of 3.8\% [198]. Through changes in electrolyte formulation and processing methodology, Im et al. have further increased the PCE to $6.5 \%$ demonstrating that methylammonium lead iodide outperformed the work horse dye N719 as light absorber material [199]. These promising first results fueled a boost in perovskite based photovoltaics (PVs), which culminated with the exceptional PCE record of more than $22 \%$ [200].

This evolution was possible on one hand through the optimization of the interlayers, which play a crucial role not only as energetic interfaces for charge extraction, but also as morphological templates and fillers, depending on whether the perovskite films are grown on the interlayer, or the latter fills the grain boundaries on the perovskite. On the other hand, major advances were obtained by modifying the perovskites composition, by selecting different chemical species to play the roles of the $\mathrm{A}, \mathrm{B}$ and $\mathrm{X}$ ions, in an $\mathrm{ABX}_{3}$ halide perovskite lattice. An example is shown in Fig. 15.

As previously mentioned, the field started off from methylammonium $\left(\mathrm{CH}_{3} \mathrm{NH}_{3}\right)$ lead iodide, with the organic compound occupying the larger cation site, and $\mathrm{Pb}$ and $\mathrm{I}$ as respectively the second cation and as the halogen anion. Successful alternatives to the use of methylammonium (ionic radius $r_{\mathrm{A}} \sim 0.18 \mathrm{~nm}$ ) are either formamidinium $\left(\mathrm{CH}\left(\mathrm{NH}_{2}\right)_{2}, \quad r_{\mathrm{A}} \sim 0.27 \mathrm{~nm}\right)$ or caesium $\left(r_{\mathrm{A}} \sim 0.165 \mathrm{~nm}\right)$, both introduced as ways to improve the stability of perovskite PVs, and generally employed in mixed-cation 


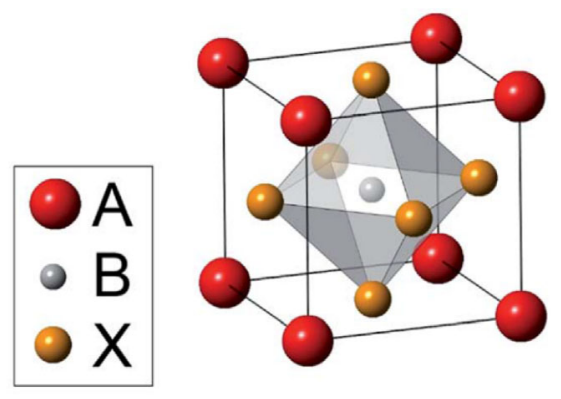

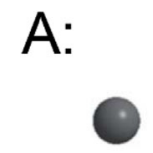

Caesium

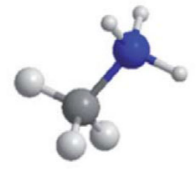

Methylammonium

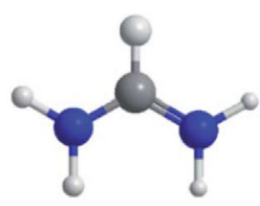

Formamidinium
Figure 15 Example structure of perovskites for photovoltaics. The A sites can be occupied by caesium (all-inorganic perovskites solar cells), methylammonium, or formamidinium; candidates for the smaller cation $\mathrm{B}$ are $\mathrm{Pb}, \mathrm{Sn}$ and $\mathrm{Bi}$, and for the $\mathrm{X}$ anions the halogens $\mathrm{F}, \mathrm{Cl}, \mathrm{Br}$ and $\mathrm{I}$ are being used in single or mixed form. Reproduced from Ref. [201] with permission of The Royal Society of Chemistry.

configurations. For the anion $\mathrm{X}$, the halogens $\mathrm{Br}$ $\left(r_{\mathrm{X}}=0.196 \mathrm{~nm}\right)$ and $\mathrm{Cl}\left(r_{\mathrm{X}}=0.181 \mathrm{~nm}\right)$ are commonly used, next to the aforementioned I $\left(r_{\mathrm{X}}=0.220 \mathrm{~nm}\right)$. Traces of $\mathrm{Cl}$ are often present in the films, since chloride salts are often used as perovskite precursors because they enhance the formation of crystalline domains. In general, $\mathrm{Pb}$ $\left(r_{\mathrm{B}}=0.119 \mathrm{~nm}\right)$ is used as B cation. However, driven by toxicity concerns, alternatives for $\mathrm{Pb}$ are being investigated, such as $\mathrm{Sn}\left(r_{\mathrm{B}}=0.110 \mathrm{~nm}\right)$ and $\mathrm{Bi}$, for which a doubleperovskite structure has also been proposed [202]. For these halide perovskites the tolerance factor $t$ is typically situated in the range $0.80<t<1.0$ [203-205].

Several combinations of the mentioned ions were synthesized, resulting in compounds that are compatible with wet deposition techniques (discussed in Sect. 3.6) and exhibit long charge-carriers lifetimes (and high charge-carrier mobilities) [206-208]. These properties make perovskites appealing candidates for a variety of electronics-related applications, as they can achieve high performances with reduced fabrication costs.

8.2 Multi-junction perovskite solar cells Nevertheless, not all of these high-mobility perovskites are equally suitable for PV applications, the main reason behind this resides in the fact that solar cells need to efficiently absorb light. The absorbance of the layer will depend on the energy bandgap of the material, which determines the lowest photon energy that can be absorbed by said material and the effectiveness of this absorption. As an example, the workhorse perovskite for $\mathrm{PV}$ applications, $\mathrm{CH}_{3} \mathrm{NH}_{3} \mathrm{PbI}_{3}$, has a direct bandgap of $\sim 1.55 \mathrm{eV}$, which allows for a nearly total collection of photons of energy higher than $1.55 \mathrm{eV}$, within roughly $300 \mathrm{~nm}$ of material (ultra-thin). While in some cases the optimization of this gap is still in progress, the tunability of this absorption band is being strongly exploited for the production of multi-junction solar cells, where the top cell absorbs most of the high-energy photons (shorter wavelengths), and the bottom one harvests the remaining lower energy photons. These tandem stacks are possible in combination with a variety of traditional and high efficiency solar cells technologies, ranging from perovskite/silicon [209, 210], perovskite/germanium [211] to perovskite/perovskite [212]. Figure 16 gives an illustration of a crystalline silicon/perovskite tandem cell, with the perovskite as the front cell for the higher-energy photon absorption and c-Si (band gap $1.12 \mathrm{eV}$ ) as the bottom cell for the lower photon energy absorption [209]. Although currently the obtained record efficiencies for the emerging perovskite based tandem cells are around 20-23\% [201, $210]$ it is expected that this route will soon lead to much higher efficiencies - therefore outperforming traditional single junction mono-crystalline silicon solar cells.

\subsection{Towards large-area and stable perovskite} solar cells The reported record efficiencies for perovskite solar cells are typically obtained on lab-scale prototype devices (typically in the range of $\mathrm{mm}^{2}-\mathrm{cm}^{2}$ ) and upscaling towards large-area production requires appropriate robust and reproducible preparation techniques. In Section 3.6 wet deposition thin-film preparation techniques have been introduced which require further developments in order to obtain large-area, pinhole-free perovskite solar cell stacks. As already mentioned, the preparation of the electron- and hole selective contact materials is also of great importance and several vacuum deposition and wet deposition routes are being investigated [213].

As is often the case with emerging technologies, prototype perovskite solar cells show stability issues under the influence of various environmental parameters such as moisture, UV-light and temperature. The underlying
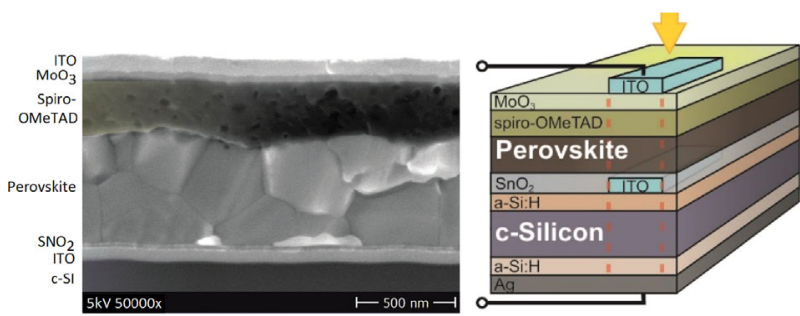

Figure 16 A cross-section of a monolithic perovskite/silicon tandem cell with a scanning electron microscopy image (left) and the schematic layout (right). The light input is from the top and the red dashed line indicates the active area. The tandem cell consists of a perovskite solar cell as the front cell for the higher energy photon absorption and of a silicon solar cell as the bottom cell for the lower photon energy absorption. Reproduced from Ref. [209] with permission of The Royal Society of Chemistry. 
degradation mechanisms are currently under study and appropriate intrinsic and extrinsic measures to prolong the operational lifetime are under investigation. In an extensive recent review on the stability of perovskite solar cells, Wang et al. [214] emphasize that the stability issues are not only limited to the perovskite photoactive material but can also occur at the interfaces between the different layers (electronand hole-transport layers, buffer layers, electrodes etc.). With an 'eye to the sky', perovskites are also being tested under unconventional degradation conditions [215]. Due to their ultra-thin absorber layers, the possibility to fabricate them on top of thin plastic foils, and their successful implementation in tandem solar cells, perovskite PVs could become a solar technology for aerospace applications [216].

Besides long-term stability issues, perovskite solar cells can suffer from hysteresis effects in current-voltage $(I-V)$ measurements conducted under illumination [217-219]. These hysteresis effects are linked to the perovskite grain size and the structure of the underlying $\mathrm{TiO}_{2}$ electron transport layer, and the underlying mechanisms proposed to be causing these effects is the low ion mobility within the perovskite layer.

The recent rise of perovskite based solar cells has been tremendously rapid and significant progress is expected on a relatively short time scale, also for the mentioned challenging issues, positioning perovskite solar cells as a disruptive class PV technology to challenge or complement the traditional and commercial ones for the next generation of solar energy conversion. This is of course only a nutshell account of the historical development of perovskite solar cells and of their future outlooks. For further details and information on the topic, we refer to other review articles including Refs. [206] and [220].

8.4 Perovskites for radiation detection and lasers Classical oxide-based perovskites such as PST (lead-scandium tantalate) are already used in the infraredsensitive detector arrays of thermographic cameras [221]. The working principle is based on the pyroelectric effect described in Sect. 6.1 and efforts in the same direction, however with $\mathrm{Pb}$-free perovskites (e.g., $\mathrm{Ba}_{0.67} \mathrm{Sr}_{0.33} \mathrm{TiO}_{3}$ ), are ongoing [222]. For the wavelength regime of visible light, Saidaminov et al. designed in 2015 metal-semiconductor-metal photodetectors with practically uniform absorption characteristics between 380 and $550 \mathrm{~nm}$ [223]: The metal was optically transparent indium-tin oxide and methylammonium lead bromide $\left(\mathrm{MAPbBr}_{3}\right)$ served as semiconductor, providing free charge carriers under photoexcitation. It is interesting to note that the perovskite layers, prepared from wet-chemical solutions, had singlecrystalline properties over length scales of more than $30 \mu \mathrm{m}$ even on a non-crystalline glass substrate. Furthermore, $\mathrm{CsPbBr}_{3}$ [55] and $\mathrm{MAPbI}_{3}$ [224, 225] are proven to have excellent absorption characteristics for $\mathrm{X}$ - and $\gamma$-rays, making them suitable for radiation detection in the shortwavelength regime. The strong absorption is evidently related to their lead contents but, in a positive sense, photoelectric $X$ - and $\gamma$-ray detectors can possibly serve for the direct conversion of radiation energy into electrical currents [224].

As an inversion of the solar cells discussed above, $\mathrm{MAPbI}_{3-x} \mathrm{Cl}_{x}$ was successfully employed as active material in light-emitting diodes with sharply defined emission peaks at $754 \mathrm{~nm}$ for electroluminescence and at $773 \mathrm{~nm}$ in case of photoluminescence [226]. Furthermore, also amplified spontaneous light emission (lasing) was demonstrated with perovskites of the $\mathrm{MAPbX}_{3}$ family $\left(\mathrm{X}: \mathrm{Cl}^{-}, \mathrm{Br}^{-}, \mathrm{I}^{-}\right)$in which the emission wavelength could be tuned in the range from 390 to $790 \mathrm{~nm}$, thus including and exceeding the entire visible spectrum [227]. Tuning of the wavelength was achieved by adjusting the ratio of the three different halides by mixing the precursor solutions.

9 Conclusions and outlook In this review we have seen how a naturally occurring mineral has become the archetype for a tremendously large class of compounds thanks to its extraordinary compositional and structural flexibility. Of course, not all facets could be discussed in detail, but it is interesting to note that many of the special properties were already well known in the period between 1950 and 1955 . This includes ferro- and antiferromagnetism, the colossal negative magnetoresistance, dielectric and piezoelectric properties, and catalytic activity. By 2016, piezoelectric perovskites are readily found in commercial applications and this holds for high- $\kappa$ dielectrics and pyroelectric perovskites as well. Regarding data storage and readout, magnetoresistive perovskite devices can so far not compete with mature metaland alloy-based techniques within the relevant temperatureand fields range. In case of catalysis, however, perovskites may soon play an important role due to limited resources of precious metals such as platinum and increasing needs in purification of exhaust gases and environmentally friendly energy storage and conversion.

The history of superconducting perovskites demonstrates how long the road from first discoveries to specialized applications can be: Although discovered already in 1975 in the $\mathrm{BaPb}_{1-x} \mathrm{Bi}_{x} \mathrm{O}_{3}$ system, it took until 1987 when YBCO was developed, the first material enabling superconductivity by liquid-nitrogen cooling. Without prior knowledge from years of basic research on the interplay between structural-, compositional-, and electronic properties, this material would possibly have never been designed. But, all over sudden, intense researchand development activities were launched, that went down again a decade later when the initially bright perspectives were seen in a more realistic way. Today, nobody awaits a superconducting power grid but in specialized research fields that rely on sensitive magnetometry or strong magnetic fields, perovskite-based superconductors have found their well-deserved place.

The recent rise of perovskite-based solar cells - with research-cell efficiency records over $22 \%$ - has been tremendously rapid, positioning perovskite solar cells as a disruptive class PV technology to challenge or complement 
the traditional and commercial ones for the next generation of solar energy conversion. As perovskite solar cells are a very recent category in photovoltaics, they are not yet inserted into the latest international photovoltaic technology road-maps (e.g., International Energy Agency IEA and International Technology Roadmap for Photovoltaic ITRPV). It is however expected that multi-junction perovskite solar cells will soon outperform traditional single-junction monocrystalline silicon solar cells. The major challenges that have to be tackled towards commercialization are related to toxicity (lead-free materials are needed), large-area production, and long-term stability. In comparison to the oxide-based high- $T_{c}$ superconductors, the halide-based photovoltaic materials offer relatively facile preparation by wet-chemical routes and this is certainly a good starting condition for prosperous evolutions in this field.

Coming back to the oxides topic, we conclude our review with a suggestion for further reading: 'The 2016 oxide electronic materials and oxide interfaces roadmap', written by not less than 44 top experts in this field, gives an excellent and complete status inventory together with a scientific and technological forecast [228]. Evolutions to come, all based on perovskites, include ferroelectric optical modulators, all-oxide solar cells, thermoelectric energy conversion, new water-splitting technologies, spin valves made of multiferroics, superconducting supermagnets and field-effect transistors with perovskite-perovskite interfaces as charge-carrier channels. And as always: Accidental observations can open the door towards unexpected breakthroughs, we just need to be prepared and carry on.

Acknowledgements The Ph.D. project of co-author Gideon Wackers is funded by FWO - Research Foundation Flanders, project no. G.0B25.14N. J. Vanacken would like to acknowledge the support from Methusalem Funding by the Flemish Government. Furthermore, the authors are grateful to Prof. Dr. Gerhard Jakob (Johannes-Gutenberg-University Mainz, Germany) for advice on the crystallographic aspects of perovskites, to Prof. Dr. Christ Glorieux (KU Leuven) for advice on pyroelectric temperature detectors, and to Prof. Dr. Margriet J. Van Bael (KU Leuven) for her input on multiferroic materials.

\section{References}

[1] O. Tschauner, C. Ma, J. R. Beckett, C. Prescher, V. B. Prakapenka, and G. R. Rossman, Science 346, 1100 (2014).

[2] G. H. Jonker and J. H. van Zanten, Physica XVI, 337 (1950).

[3] V. M. Goldschmidt, Naturwissenschaften 14, 477 (1926).

[4] H. D. Megaw, Proc. Phys. Soc. LVIII, 133 (1945).

[5] J. H. van Santen and G. H. Jonker, Physica XVI, 599 (1950).

[6] J. Volger, Physica XX, 49 (1954).

[7] G. Parravano, J. Am. Chem. Soc. 75, 1497 (1953).

[8] R. von Helmolt, J. Wecker, B. Holzapfel, L. Schultz, and K. Samwer, Phys. Rev. Lett. 71, 2331 (1993).

[9] J. G. Bednorz and K. A. Müller, Zeitschrift für Physik B Condensed Matter 64, 189 (1986).

[10] G. Rupprecht and R. O. Bell, Phys. Rev. 135, A748 (1964).
[11] R. E. Wasylichen, O. Knop, and J. B. Macdonald, Solid State Comm. 56, 581 (1985).

[12] L. Etgar, P. Gao, Z. Xue, Q. Peng, A. K. Chandiran, B. Liu, Md. K. Nazeeruddin, and M. Grätzel, J. Am. Chem. Soc. 134, 17396 (2012).

[13] H. J. Snaith, J. Physical Chem. Lett. 4, 3623 (2013).

[14] K.-I. Kobayashi, T. Kimura, H. Sawada, K. Terakura, and Y. Tokura, Nature 395, 677 (1998).

[15] R. S. Kumar, D. Prabhakaran, A. Boothroyd, M. F. Nicol, and A. Cornelius, J. Phys. Chem. Sol. 67, 2046 (2006).

[16] M. L. Moreira, E. C. Paris, G. S. do Nascimento, V. M. Longo, J. R. Sambrano, V. R. Mastelaro, M. I. B. Bernardi, J. Andrés, J. A. Varela, and E. Longo, Acta Materialia 57, 5147 (2009).

[17] T. Sato, S. Takagi, S. Deledda, B. C. Hauback, and S. Orimo, Sci. Rep. 6, art. no. 2953210 pp (2016).

[18] H. A. Jahn and E. Teller, Proc. Roy. Soc. A 161, 220 (1937).

[19] A. J. Millis, Phys. Rev. B 53, 8 (1996).

[20] J. Rodríguez-Carvajal, M. Hennion, F. Moussa, A. H. Moudden, L. Pinsard, and A. Revcolevschi, Phys. Rev. B 57, R3189 (1998).

[21] S. Margadonna and G. Karotsis, J. Mater. Chem. 17, 2013 (2007).

[22] The denominations $3 z^{2}-r^{2}$ and $x^{2}-y^{2}$ refer to the orbitals' shapes, independent of their actual orientation along certain crystallographic axes.

[23] H.-T. Jeng, S.-H. Lin, and C.-S. Hsue, Phys. Rev. Lett. 97, art. no. 0670024 pp (2006).

[24] L. D. Tung, J. Schefer, M. R. Lees, G. Balakrishnan, and D. McKenzie Paul, J. Sci.: Adv. Mater. Devices 1, 174 (2016).

[25] J. Varignon, N. C. Bristowe, E. Bousquet, and P. Ghosez, Sci. Rep. 5, art. no. 1536411 pp (2015).

[26] K. Knížek, Z. Jirák, E. Pollert, F. Zounová, and S. Vratislav, J. Solid State Chem. 100, 292 (1992).

[27] S. B. Wilkins, T. A. W. Beale, P. D. Hatton, J. A. Purton, P. Bencok, D. Prabhakaran, and A. T. Boothroyd, New J. Phys. 7, art. no. 8011 pp (2005).

[28] J. B. Goodenough and J.-S. Zhou, J. Mater. Chem. 17, 2394 (2007).

[29] T. Mizokawa and A. Fujimori, Phys. Rev. B 54, 5368 (1996).

[30] E. J. W. Verwey and P. W. Haayman, Physica VIII, 979 E. J. W. Verwey, Nature 1939, 144, 327 (1941).

[31] J. P. Attfield, Solid State Sci. 8, 861 (2006).

[32] Y. Tomioka, A. Asamitsu, Y. Moritomo, H. Kuwahara, and Y. Tokura, Phys. Rev. Lett. 74, 5108 (1995).

[33] T. Vogt, A. K. Cheetham, R. Mahendiran, A. K. Raychaudhuri, R. Mahesh, and C. N. R. Rao, Phys. Rev. B 54, 15303 (1996).

[34] C. N. R. Rao and A. K. Cheetham, Science 276, 911 (1997).

[35] C. N. R. Rao, A. Aruljaj, A. K. Cheetham, and B. Raveau, J. Phys. Condens. Matter 12, R83 (2000).

[36] S. Kawasaki, M. Takano, R. Kanno, T. Takeda, and A. Fujimori, Jpn. J. Phys. Soc. 67, 1529 (1998).

[37] P. M. Woodward, D. E. Cox, E. Moshopoulu, A. W. Sleight, and S. Moritomo, Phys. Rev. B 62, 844 (2000).

[38] J. Shi, Y. Zhou, and S. Ramanathan, Nature Commun. 5, art. no. 48609 pp (2014).

[39] A. F. Corsmit, H. E. Hoefdraad, and G. Blasse, J. Inorg. Nucl. Chem. 34, 3401 (1972).

[40] W. Westerburg, D. Reisinger, and G. Jakob, Phys. Rev. B 62, R767 (2000). 
[41] S. Vasala and M. Karppinen, Prog. Solid State Chem. 43, 1 (2015).

[42] S. N. Ruddlesden and P. Popper, Acta Crystallogr. 10, 538 (1957).

[43] S. N. Ruddlesden and P. Popper, Acta Crystallogr. 11, 54 (1958).

[44] R. Suryanarayanen, G. Dhalenne, A. Revcolevschi, W. Prellier, J.-P. Renard, C. Dupas, W. Caliebe, and T. Chatterji, Solid State Comm. 113, 267 (2000).

[45] H. P. Roeser, F. Hetfleisch, D. T. Haslam, J. S. Lopez, M. Stepper, J. Vernerey, F. M. Huber, M. F. von Schoenermark, and A. S. Nikoghosyan, Acta Astronautica 66, 637 (2010).

[46] R. H. Mitchell, Perovskites: Modern and Ancient, Almaz Press Inc., Thunder Bay, Ontario CanadaISBN, 0-96894110-9, 2002.

[47] H.-U. Habermeier, Materials Today 10, 34 (2007).

[48] C. Rodenbücher, M. Luysberg, A. Schwedt, V. Havel, F. Gunkel, J. Mayer, and R. Waser, Sci. Rep. 6, art. no. 32250 8 pp (2016).

[49] J. C. Guitel, M. Marezio, and J. Mareschal, Mater. Res. Bull. 11, 739 (1976).

[50] Y. Miyazawa, H. Toshima, and S. Morita, J. Cryst. Growth 128, 668 (1993).

[51] D. Shulyatev, S. Karabashev, A. Arsenov, and Y. Mukovskii, J. Cryst. Growth 198/199, 511 (1999).

[52] N. Kikugawa, R. Baumbach, J. S. Brooks, T. Terashima, S. Uji, and Y. Maeno, Cryst. Growth \& Des. 15, 5573 (2015).

[53] P. Reutler, O. Friedt, B. Büchner, M. Braden, and A. Revcolevschi, J. Cryst. Growth 249, 222 (2003).

[54] A. Benayad, G. Sebald, L. Lebrun, B. Guiffard, S. Pruvost, D. Guyomar, and L. Beylat, Mater. Res. Bull. 41, 1069 (2006).

[55] C. C. Stoumpos, C. D. Maliakas, J. A. Peters, Z. Liu, M. Sebastian, J. Im, T. C. Chasapis, A. C. Wibowo, D. Y. Chung, A. J. Freeman, B. W. Wessels, and M. G. Kanatzidis, Cryst. Growth Des. 13, 2722 (2013).

[56] M. I. Saidaminov, A. L. Abdelhady, B. Murali, E. Alarousu, V. M. Burlakov, W. Peng, I. Dursun, L. Wang, Y. He, G. Maculan, A. Goriely, T. Wu, O. F. Mohammed, and O. M. Bakr, Nature Commun. 6, art. no. 75866 pp (2015).

[57] R. L. Sandstrom, E. A. Giess, W. J. Gallagher, A. Segmüller, E. I. Cooper, M. F. Chisholm, A. Gupta, S. Shinde, and R. B. Laibowitz, Appl. Phys. Lett. 53, 1874 (1988).

[58] R. A. Cowley, Phys. Rev. 134, A981 (1964).

[59] P. J. Kelly and R. D. Arnell, Vacuum 56, 159 (2000).

[60] I. Safi, Surf. Coating Technol. 127, 203 (2000).

[61] G. Bräuer, B. Szyska, M. Vergöhl, and R. Bandorf, Vacuum 84, 1354 (2010).

[62] U. Poppe, J. Schubert, R. R. Arons, W. Evers, C. H. Freiburg, W. Reichert, K. Schmidt, W. Sybertz, and K. Urban, Solid State Comm. 66, 661 (1988).

[63] P. Wagner, H. Adrian, and C. Tomé-Rosa, Phys. C 195, 258 (1992).

[64] P. Wagner, U. Frey, F. Hillmer, and H. Adrian, Phys. Rev. B 51, 1206 (1995).

[65] S. R. Curras, G. Ferro, M. T. González, M. V. Ramallo, M. Ruibal, J. A. Veira, P. Wagner, and F. Vidal, Phys. Rev. B 68, art. no. 09450116 pp (2003).

[66] P. R. Willmott and J. R. Huber, Rev. Mod. Phys. 72, 31 (2000).
[67] M. Opel, J. Phys. D: Appl. Phys. 45, art. no. 03300131 pp (2012).

[68] Public domain figure, www.egr.msu.edu/eceshop/ testingfacility/laser/, hosted by Michigan State University College of Engineering, accessed on June 15, 2017.

[69] S. Jin, T. H. Tiefel, M. McCormack, R. A. Fastnacht, R. Ramesh, and L. H. Chen, Science 264, 413 (1994).

[70] A. Thiessen, E. Beyreuther, R. Werner, D. Koelle, R. Kleiner, and L. M. Eng, J. Phys. Chem. Solids 80, 26 (2015).

[71] G. Catalan, R. M. Bowman, and J. M. Gregg, Phys. Rev. B 62, 7892 (2000).

[72] T. Ohnishi, M. Lippmaa, T. Yamamoto, S. Meguro, and H. Koinuma, Appl. Phys. Lett. 87, art. no. 2419193 pp (2005).

[73] C. Huck, A. Poghossian, M. Bäcker, S. Chaudhury, W. Zander, J. Schubert, V. K. Begoyan, V. V. Buniatyan, P. Wagner, and M. J. Schöning, Sens. Actuator B - Chem. 198, 102 (2014).

[74] D. Fuchs, E. Arac, C. Pinta, S. Schuppler, R. Schneider, and H. von Löhneisen, Phys. Rev. B 77, art. no. 0144348 pp (2008).

[75] D. H. Kim, H. N. Lee, M. Varela, and H. M. Christen, Appl. Phys. Lett. 89, art. no. 1629043 pp (2006).

[76] D. Sánchez, M. Garcia-Hernández, N. Auth, and G. Jakob, J. Appl. Phys. 96, 2736 (2004).

[77] M. P. Singh, C. Grygiel, W. C. Sheets, Ph. Boullay, M. Hervieu, W. Prellier, B. Mercey, Ch. Simon, and B. Raveau, Appl. Phys. Lett. 91, art. no. 0125033 pp (2007).

[78] M. Lorenz, V. Lazenka, P. Schwinkendorf, F. Bern, M. Ziese, H. Modarresi, A. Volodin, M. J. Van Bael, K. Temst, A. Vantomme, and M. Grundmann, J. Phys. D: Appl. Phys. 47, art. no. 13530311 pp (2014).

[79] J. Verbeeck, S. Bals, A. N. Kravtsova, D. Lamoen, M. Luysberg, M. Huijben, G. Rijnders, A. Brinkman, H. Hilgenkamp, D. H. A. Blank, and G. Van Tendeloo, Phys. Rev. B 81, art. no. 0851136 pp (2010).

[80] J.-P. Locquet, J. Perret, J. Fompeyrine, E. Mächler, J. W. Seo, and G. Van Tendeloo, Nature 394, 453 (1998).

[81] P. Wagner, F. Hillmer, U. Frey, H. Adrian, T. Steinborn, L. Ranno, A. Elschner, I. Heyvaert, and Y. Bruynseraede, Phys. C 215, 123 (1993).

[82] A. Thiessen, E. Beyreuther, R. Werner, R. Kleiner, D. Koelle, and L. M. Eng, J. Phys.: Condens. Matter 27, art. no. $02550311 \mathrm{pp}$ (2015).

[83] A. T. Barrows, A. J. Pearson, C. K. Kwak, A. D. F. Dunbar, A. R. Buckley, and D. G. Lidzey, Energy Environ. Sci. 7, 2944 (2014).

[84] S. Razza, S. Castro-Hermosa, A. Di Carlo, and T. M. Brown, APL Mater. 4, art. no. 09150815 pp (2016).

[85] A. Mei, X. Li, L. Liu, Z. Ku, T. Liu, Y. Rong, M. Xu, M. Hu, J. Chen, Y. Yang, M. Grätzel, and H. Han, Science 345, 295 (2014).

[86] Y. Zhao and K. Zhu, Chem. Soc. Rev. 45, 655 (2016).

[87] M. M. Lee, J. Teuscher, T. Miyasaka, T. N. Murakami, and H. J. Snaith, Science 338, 643 (2012).

[88] B. Conings, S. A. Bretschneider, A. Babayigit, N. Gauquelin, I. Cardinaletti, J. V. Manca, J. Verbeeck, H. J. Snaith, and H.-G. Boyen, ACS Appl. Mater. Interfaces 9, 8092 (2017).

[89] W. Qiu, T. Merckx, M. Jaysankar, C. Masse de la Huerta, L. Rakocevic, W. Zhang, U. W. Paetzold, R. Gehlhaar, L. Froyen, J. Poortmans, D. Cheyns, H. J. Snaith, and P. Heremans, Energy \& Env. Sci. 9, 484 (2016). 
[90] B. Conings, L. Baeten, C. De Dobbelaere, J. D'Haen, J. Manca, and H.-G. Boyen, Adv. Mater. 26, 2041 (2014).

[91] J. Burschka, N. Pellet, S. J. Moon, R. Humphry-Baker, P. Gao, M. K. Nazeeruddin, and M. Grätzel, Nature 499, 316 (2013).

[92] W. Qiu, J. P. Bastos, S. Dasgupta, T. Merckx, I. Cardinaletti, M. V. C. Jenart, C. B. Nielsen, R. Gehlhaar, J. Poortmans, P. Heremans, I. McCulloch, and D. Cheyns, J. Mater. Chem. A 5, 2466 (2017).

[93] M. Liu, M. B. Johnston, and H. J. Snaith, Nature 501, 395 (2013).

[94] C. Momblona, L. Gil-Escrig, E. Bandiello, E. M. Hutter, M. Sessolo, K. Lederer, J. Blochwitz-Nimoth, and H. J. Bolink, Energy Environ. Sci. 9, 3456 (2016).

[95] M. R. Leyden, Y. Jiang, and Y. Qi, J. Mater. Chem. A 4, 13125 (2016).

[96] N. Ledermann, P. Muralt, J. Baborowski, S. Gentil, K. Mukati, M. Cantoni, A. Seifert, and N. Setter, Sens. \& Act. A 105, 162 (2003).

[97] R. W. Schwartz, Chem. Mater. 9, 2325 (1997).

[98] P. Grünberg, R. Schreiber, Y. Pang, M. B. Brodsky, and H. Sowers, Phys. Rev. Lett. 57, 2442 (1986).

[99] M. N. Baibich, J. M. Broto, A. Fert, F. N. Vandau, F. Petroff, P. Eitenne, G. Creuzet, A. Friederich, and J. Chazelas, Phys. Rev. Lett. 61, 2472 (1988).

[100] N. D. Mathur, G. Burnell, S. P. Isaac, T. J. Jackson, B.-S. Teo, J. L. MacManus-Driscoll, L. F. Cohen, J. E. Evetts, and M. G. Blamire, Nature 387, 266 (1997).

[101] P. Wagner, I. Gordon, L. Trappeniers, J. Vanacken, F. Herlach, V. V. Moshchalkov, and Y. Bruynseraede, Phys. Rev. Lett. 81, 3980 (1998).

[102] I. Gordon, P. Wagner, V. V. Moshchalkov, Y. Bruynseraede, M. Apostu, R. Suryanarayanan, and A. Revco-levschi, Phys. Rev. B. 64, art. no. 0924084 pp (2001).

[103] J. M. Doughton, J. Mag. Mag. Mat. 192, 334 (1999).

[104] W. Kwiatkowski and S. Tumanski, J. Phys. E. - Scientific Instrum. 19, 502 (1986).

[105] C. Zener, Phys. Rev. 82, 403 (1951).

[106] J. M. De Teresa, M. R. Ibarra, P. A. Algarabel, C. Ritter, C. Marquina, J. Blasco, J. García, A. del Moral, and Z. Arnold, Nature 386, 256 (1997).

[107] G. Jakob, W. Westerburg, F. Martin, and H. Adrian, Phys. Rev. B 58, 14966 (1998).

[108] M. Fiebig, K. Miyano, Y. Tomioka, and Y. Tokura, Science 280, 1925 (1998).

[109] M. Fäth, S. Freisem, A. A. Menovsky, Y. Tomioka, J. Aarts, and J. A. Mydosh, Science 285, 1540 (1999).

[110] P. Wagner, D. Mazilu, L. Trappeniers, V. V. Moshchalkov, and Y. Bruynseraede, Phys. Rev. B 55, R14721 (1997).

[111] G. Jakob, F. Martin, W. Westerburg, and H. Adrian, Phys. Rev. B 57, 10252 (1998).

[112] L. Berger, Phys. Rev. B 2, 4559 (1970).

[113] P. Wagner, I. Gordon, A. Vantomme, D. Dierickx, M. J. Van Bael, V. V. Moshchalkov, and Y. Bruynseraede, Europhys. Lett. 41, 49 (1998).

[114] W. E. Pickett and D. J. Singh, Phys. Rev. B 55, R8642 (1997).

[115] I. Gordon, P. Wagner, A. Das, J. Vanacken, V. V. Moshchalkov, Y. Bruynseraede, W. Schuddinck, G. Van Tendeloo, M. Ziese, and G. Borghs, Phys. Rev. B 62, 11633 (2000).
[116] M. Respaud, J. M. Broto, H. Rakoto, J. Vanacken, P. Wagner, C. Martin, A. Maignan, and B. Raveau, Phys. Rev. B 63, art. no. 1444266 pp (2001).

[117] M. Malfait, I. Gordon, V. V. Moshchalkov, Y. Bruynseraede, G. Borghs, and P. Wagner, Phys. Rev. B 68, art. no. 1324104 pp (2003).

[118] A. Fert and D. K. Lottis, Concise Encyclopedia of Magnetic and Superconducting Materials. (Ed.: J. Evetts), Pergamon Press, 1992.

[119] Colossal magnetoresistive oxides. (Ed.: Y. Tokura), Gordon and Breach Science Publishers, Amsterdam, The Netherlands ISBN 90-5699-231-7 2000.

[120] A. P. Ramirez, J. Phys. Condens. Matter 9, 8171 (1997).

[121] J. M. D. Coey, M. Viret, and S. von Molnár, Adv. Phys. 48, 167 (1999).

[122] D. Serrate, J. M. De Teresa, and M. R. Ibarra, J. Phys.: Condens. Matter 19, art. no. 02320186 pp (2007).

[123] A. W. Sleight, J. L. Gillson, and P. E. Bierstedt, Solid State Commun. 17, 27 (1975).

[124] N. V. Anshukova, A. I. Golovashkin, L. I. Ivanova, O. T. Malyuchkov, and A. P. Rusakov, JETP 81, 1163 (1995).

[125] M. K. Wu, J. R. Ashburn, C. J. Torng, P. H. Hor, R. L. Meng, J. Gao, Z. J. Huang, Y. Q. Wang, and C. W. Chu, Phys. Rev. Lett. 58, 908 (1987).

[126] J. M. Tarascon, W. R. McKinnon, P. Barboux, D. M. Hwang, B. G. Bagley, L. H. Greene, G. W. Hull, N. Stoffel, and M. Giroud, Phys. Rev. B 38, 8885 (1988).

[127] R. Kleiner, W. Buckel, and R. Huebener, Superconductivity: An Introduction, 3rd edn, ISBN: 978-3-527-41162-7, Wiley-VCH (2015).

[128] M. Hervieu, C. Michel, A. Maignan, C. Martin, and B. Raveau, J. Solid State Chem. 74, 428 (1988).

[129] C. W. Chu, L. Gao, F. Chen, Z. J. Huang, R. L. Meng, and Y. Y. Xue, Nature 365, 323 (1993).

[130] A. P. Drozdov, M. I. Eremets, I. A. Troyan, V. Ksenvontov, and S. I. Shylin, Nature 525, 73 (2015).

[131] E. H. Brandt, Rep. Progress in Phys. 58, 1465 (1995).

[132] M. Xu, D. L. Shi, and R. F. Fox, Phys. Rev. B 42, 10773 (1990).

[133] E. F. Talantsev and J. L. Tallon, Nat. Comm. 6, art. no. 7820 8 pp (2015).

[134] N. Chikumoto, K. Furusawa, and M. Murakami, Phys. C 412-412, 463 (2004).

[135] H. Matsui, T. Ootsuka, H. Ogiso, H. Yamasaki, M. SOhma, I. Yamaguchi, T. Kumagai, and T. Manabe, Supercond. Sci. Technol. 29, art. no. 0650028 pp (2016).

[136] P. Wagner, F. Hillmer, U. Frey, and H. Adrian, Phys. Rev. B 49, 13184 (1994).

[137] D. C. Larbalestier, J. Jiang, U. P. Trociewitz, F. Kametani, C. Scheuerlein, M. Dalban-Canassy, M. Matras, P. Chen, N. C. Craig, P. J. Lee, and E. E. Hellstrom, Nat. Mater. 13, 375 (2014).

[138] C. Senatore, C. Barth, M. Bonura, M. Kulich, and G. Modonico, Supercond. Sci. Technol. 29, art. no. 0140028 pp (2016).

[139] G. Jakob, M. Schmitt, Th. Kluge, C. Tomé-Rosa, P. Wagner, Th. Hahn, and H. Adrian, Phys. Rev. B. 47, 12099 (1993).

[140] C. Gerber, D. Anselmetti, J. G. Bednorz, J. Mannhart, and D. G. Schlom, Nature 350, 279 (1991). 
[141] C. Tome Rosa, G. Jakob, M. Maul, A. Walkenhorst, M. Schmitt, P. Wagner, P. Przyslupski, and H. Adrian, Phys. C 171, 231 (1990).

[142] M. Speckmann, T. Kluge, C. Tome Rosa, T. Becherer, and H. Adrian, Phys. Rev. B 47, 15185 (1993).

[143] L. Trappeniers, J. Vanacken, L. Weckhuysen, K. Rosseel, A. Y. Didyk, I. N. Goncharov, L. I. Leonyuk, W. Boon, F. Herlach, V. V. Moshchalkov, and Y. Bruynseraede, Phys. C 313, 1 (1999).

[144] K. Rosseel, D. Dierickx, J. Lapin, V. V. Metlushko, W. Boon, L. Trappeniers, J. Vanacken, F. Herlach, V. V. Moshchalkov, Y. Bruynseraede, O. VanderBiest, L. Reylandt, and F. Delannay, Appl. Supercon. 148, 279 (1995).

[145] A. Llordes, A. Palau, J. Gazquez, M. Coll, R. Vlad, A. Pomar, J. Arbiol, R. Guzman, S. Ye, V. Rouco, F. Sandiumenge, S. Ricart, T. Puig, M. Varela, D. Chateigner, J. Vanacken, J. Gutierrez, V. V. Moshchalkov, G. Deutscher, C. Magen, and X. Obradors, Nat. Mat. 11, 329 (2012).

[146] German Industry Standard DIN VDE 0298 T4 08/03, www. din.de.

[147] A. H. Miklich, D. Koelle, E. Dantsker, D. T. Nemeth, J. J. Kingston, R. F. Kromann, and J. Clarke, IEEE Trans. Appl. Supercon. 3, 2434 (1993).

[148] B. Mayer, L. Alff, T. Traeuble, R. Gross, P. Wagner, and H. Adrian, Appl. Phys. Lett. 63, 996 (1993).

[149] D. Koelle, R. Kleiner, F. Ludwig, E. Dantsker, and J. Clark, Rev. Mod. Phys. 71, 631 (1999).

[150] K. Herrmann, Y. Zhang, H.-M. Mück, J. Schubert, W. Zander, and A. I. Braginski, Supercond. Sci. Technol. 4, 583 (1991).

[151] J. Z. Sun, W. J. Gallagher, A. C. Callegari, V. Foglietti, and R. H. Koch, Appl. Phys. Lett. 63, 1561 (1993).

[152] Y. Zhang, G. Panaitov, S. G. Wang, N. Wolters, R. Otto, J. Schubert, W. Zander, H. J. Krause, H. Soltner, H. Bousack, and A. I. Braginski, Appl. Phys. Lett. 76, 906 (2000).

[153] L. Qiu, Y. Zhang, H.-J. Krause, A. I. Braginski, M. Burghoff, and L. Trahms, Appl. Phys. Lett. 91, art. no. 0725053 pp (2007).

[154] M. I. Faley, E. A. Kostyurina, P. Diehle, U. Poppe, A. Kovacs, Y. V. Maslennikov, V. P. Koshelets, and R. E. Dunin-Borkowski, IEEE Trans. Appl. Supercon. 27, art. no. 16009055 pp (2017).

[155] A. Ohtomo and H. Y. Hwang, Nature 427, 423 (2004).

[156] A. D. Caviglia, S. Gariglio, N. Reyren, D. Jaccard, T. Schneider, M. Gabay, S. Thiel, G. Hammerl, J. Mannhart, and J.-M. Triscone, Nature 456, 624 (2008).

[157] C. Richter, H. Boschker, W. Dietsche, E. Fillis-Tsirakis, R. Jany, F. Loder, L. F. Kourkoutis, D. A. Muller, J. R. Kirtley, C. W. Schneider, and J. Mannhart, Nature 502, 528 (2013).

[158] J. Bardeen, L. N. Cooper, and J. R. Schrieffer, Phys. Rev. 108, 1175 (1957).

[159] J. H. Barrett, Phys. Rev. 86, 118 (1952).

[160] M. D. Waugh, Electronic Engineering Times Europe, issue August 2010, 34-36 (2010), www.eetimes.com.

[161] H. Borkar, A. Barvat, P. Pal, A. K. Shukla, J. J. Pulikkotil, and A. Kumar, J. Appl. Phys. 119, art. no. 2141016 pp (2016).

[162] C. Rossel, B. Mereu, C. Marchiori, D. Caimi, M. Sousa, A. Guiller, H. Siegwart, R. Germann, J.-P. Locquet, J. Fompeyrine, D. J. Webb, Ch. Dieker, and J. W. Seo, Appl. Phys. Lett. 89, art. no. 0535063 pp (2006).
[163] D. I. Khomskii, J. Magnetism \& Magnetic Mater. 306, 1 (2006).

[164] M. Chirtoc and G. Mihailescu, Phys. Rev. B 40, 9606 (1989).

[165] J. Caerels, C. Glorieux, and J. Thoen, Rev. Sci. Instr. 69, 2452 (1998)

[166] P. K. Panda and B. Shoo, Ferroelectrics 474, 128 (2015).

[167] M. S. Vijaya, Piezoelectric Materials and Devices: Applications in Engineering and Medical Sciences. CRC Press, Boca Raton, Florida, US ISBN 97814398878682012.

[168] G. T. Hwang, M. Byun, C. K. Jeong, and K. J. Lee, Adv. Healthcare Mater. 4, 646 (2015).

[169] T. R. Shrout and S. J. Zhang, J. Electroceram. 19, 111 (2007).

[170] W. Liu and X. Ren, Phys. Rev. Lett. 103, art. no. 2576024 pp (2009).

[171] A. Batagiannis, M. Wübbenhorst, and J. Hulliger, Curr. Opin. Solid State Mater. Sci. 14, 107 (2010).

[172] N. Nuraje and K. Su, Nanoscale 5, 8752 (2013).

[173] M. Fiebig, J. Phys. D: Appl. Phys. 38, R123 (2005).

[174] S. W. Cheong and M. Mostovoy, Nat. Mater. 6, 13 (2007).

[175] B. B. van Aken, T. T. M. Palstra, A. Filipetti, and N. A. Spaldin, Nat. Mater. 3, 164 (2004).

[176] C. Ederer and N. Spaldin, Phys. Rev. B 71, art. no. 060401 (R) 4 pp (2005).

[177] V. V. Lazenka, G. Zhang, J. Vanacken, I. I. Makoed, A. F. Ravinski, and V. V. Moshchalkov, J. Phys. D: Appl. Phys. 45, art. no. 1250027 pp (2012).

[178] N. Pavlovic, J. D'Haen, H. Modarresi, A. Riskin, C. De Dobbelaere, M. J. Van Bael, K. Temst, A. Hardy, and M. K. Van Bael, J. Mater. Chem. 50, 4463 (2015).

[179] V. Lazenka, M. Lorenz, H. Modarresi, M. Bisht, R. Rüffer, M. Bonholzer, M. Grundmann, M. J. Van Bael, A. Vantomme, and K. Temst, Appl. Phys. Lett. 106, art. No. 0829044 pp (2015).

[180] R. Ramesh and N. A. Spaldin, Nat. Mater. 6, 21 (2007).

[181] R. J. H. Voorhoeve, J. P. Remeika, and L. E. Trimble, Ann. N. Y. Acad. Sci. 272, 3 (1976).

[182] R. J. H. Voorhoeve, D. W. Johnson, J. P. Remeika, and P. K. Gallagher, Science 195, 827 (1977).

[183] S. Keav, S. K. Matam, D. Ferri, and A. Weidenkaff, Catalysts 4, 226 (2014).

[184] Y. Nishihata, J. Mizuki, T. Akao, H. Tanaka, M. Uenishi, M. Kimura, T. Okamoto and N. Hamada, Nature 418, 164(2002).

[185] J. Zhu, H. Li, L. Zhong, P. Xiao, X. Xu, X. Yang, Z. Zhao, and J. Li, ACS Catal. 4, 2917 (2014).

[186] L. Forni and I. Rosetti, Appl. Catal. B: Env. 38, 29 (2002).

[187] E. A. Lombardo and M. A. Ulla, Res. Chem. Intermed. 24, 581 (1998).

[188] H. X. Dai, C. F. Ng, and C. T. Au, J. Catalysis 189, 52 (2000).

[189] A. Weidenkaff, Adv. Eng. Mater. 6, 709 (2004).

[190] T. Takeguchi, T. Yamanaka, H. Takahashi, H. Watanabe, T. Kuroki, H. Nakanishi, Y. Orikasa, Y. Uchimoto, H. Takano, N. Ohguri, M. Matsuda, T. Murota, K. Uosaki, and W. Ueda, J. Am. Chem. Soc. 135, 11125 (2013).

[191] J.-I. Jung, H. Y. Jeong, J.-S. Lee, M. G. Kim, and J. Cho, Angew. Chem. Int. Ed. 53, 4582 (2014).

[192] B. Zhao, L. Zhang, D. Zhen, S. Yoo, Y. Ding, D. Chen, Y. Chen, Q. Zhang, B. Doyle, X. Xiong, and M. Liu, Nat. Comm. 8, art. no. 145869 pp (2017). 
[193] A. Grimaud, K. J. May, C. E. Carlton, Y.-L. Lee, M. Risch, W. T. Hong, J. Zhou, and Y. Shao-Horn, Nat. Comm. 4, art. no. 24397 pp (2013).

[194] H. Zhu, P. Zhang, and S. Dai, ACS Catal. 5, 6370 (2015).

[195] J. G. Lee, J. Hwang, H. J. Hwang, O. S. Jeon, J. Jang, O. Kwon, Y. Lee, B. Han, and Y.-G. Shul, J. Am. Chem. Soc. 138, 3541 (2016).

[196] N. H. Menzler, F. Tietz, S. Uhlenbruck, H. P. Buchkremer and D. Stöver, J. Mater. Sci. 45, 2109 (2010).

[197] Y.-H. Huang, R. I. Dass, Z.-L. Xing, and J. B. Goodenough, Science 312, 254 (2006).

[198] A. Kojima, K. Teshima, Y. Shirai, and T. Miyasaka, J. Am. Chem. Soc. 131, 6050 (2009).

[199] J. H. Im, C. R. Lee, J. W. Lee, S. W. Park, and N. G. Park, Nanoscale 3, 4088 (2011).

[200] National Renewable Energy Laboratory - Best research cell-efficiency chart (2017), www.nrel.gov.

[201] G. E. Eperon, S. D. Stranks, C. Menelaou, M. B. Johnston, L. M. Herz, and H. J. Snaith, Energy Environ. Sci. 7, 982 (2014).

[202] A. H. Slavney, T. Hu, A. M. Lindenberg, and H. I. Karunadasa, J. Am. Chem. Soc. 138, 2138 (2016).

[203] N. G. Park, Mater. Today 18, 65 (2015).

[204] Z. Li, M. Yang, J.-S. Park, S.-H. Wei, J. J. Berry, and K. Zhu, Chem. Mater. 28, 284 (2016).

[205] M. Saliba, T. Matsui, J.-Y. Seo, K. Domanski, J. P. CorreaBaena, M. K. Nazeeruddin, S. M. Zakeeruddin, W. Tress, A. Abate, A. Hagfeldt, and M. Grätzel, Energy Environ. Sci 9, 1989 (2016).

[206] M. Grätzel, Nat. Mater. 13, 838 (2014).

[207] C. Wehrenfennig, M. Z. Liu, H. J. Snaith, M. B. Johnston, and L. M. Herz, Energy Env. Sci. 7, 2269 (2014).

[208] D. DeQuillettes, S. M. Vorpahl, S. 1 D. Stranks, H. Nagaoka, G. E. Eperon, M. E. Ziffer, H. J. Snaith, and D. S. Ginger, Science 348, 683 (2015).

[209] S. Albrecht, M. Saliba, J. P. Correa Baena, F. Lang, L. Kegelmann, M. Mews, L. Steier, A. Abate, J. Rappich, L. Korte, R. Schlatmann, M. K. Nazeeruddin, A. Hagfeldt, M. Grätzel, and B. Rech, Energy Env. Sci. 9, 81 (2016).

[210] B. Chen, Y. Bai, Z. Yu, T. Li, X. Zheng, Q. Dong, L. Shen, M. Boccard, A. Gruverman, Z. Holman, and J. Huang, Adv. Energy Mater. 6, art. no.1601128 7 pp (2016).

[211] W. Zi, X. Ren, X. Ren, Q. Wei, F. Gao, and S. F. Liu, Opt. Commun. 380, 1 (2016).

[212] G. Eperon, T. Leijtens, K. A. Bush, R. Prasanna, T. Green, J. T. W. Wang, D. P. McMeekin, G. Volonakis, R. L. Milot, R. May, A. Palmstrom, D. J. Slotcavage, R. A. Belisle, J. B. Patel, E. S. Parrott, R. J. Sutton, W. Ma, F. Moghadam, B. Conings, A. Babayigit, H. G. Boyen, S. Bent, F. Giustino, L. Herz, M. B. Johnston, M. D. McGehee, and H. J. Snaith, Science 354, 861 (2016).

[213] G. Adam, M. Kaltenbrunner, E. D. Glowacki, D. H. Apaydin, M. S. White, H. Heilbrunner, S. Tombe, P.
Stadler, B. Ernecker, C. W. Klampfl, N. S. Sariciftci, and M. C. Scharber, Solar Energy Materials \& Solar Cells 157, 318 (2016).

[214] D. Wang, M. Wright, N. K. Elumalai, and A. Uddin, Solar Energy Mater. \& Solar Cells 147, 255 (2016).

[215] F. Lang, N. H. Nickel, J. Bundesmann, S. Seidel, A. Denker, S. Albrecht, V. V. Brus, J. Rappich, B. Rech, G. Landi, and H. C. Neitzert, Adv. Mater. 28, 8726 (2016).

[216] M. Kaltenbrunner, G. Adam, E. D. Glowacki, M. Drack, R. Schwödiauer, L. Leonat, D. H. Apaydin, H. Groiss, M. C. Scharber, M. S. White, N. S. Sariciftci, and S. Bauer, Nat. Mater. 14, 1032 (2015).

[217] H. J. Snaith, A. Abate, J. M. Ball, G. E. Eperon, T. Leijtens, N. K. Noel, S. D. Stranks, J. T. -Wang, K. Wojciechowski, and W. Zhang, J. Phys. Chem. Lett. 5, 1511 (2014).

[218] H.-S. Kim and N.-G. Park, J. Phys. Chem. Lett. 5, 2927 (2014).

[219] E. L. Unger, E. T. Hoke, C. D. Bailie, W. H. Nguyen, A. R. Bowring, T. Heumuller, M. G. Christoforo, and M. D. McGehee, Energy Environ. Sci. 7, 3690 (2014).

[220] H. J. Snaith, J. Phys. Chem. Lett. 4, 3623 (2013).

[221] M. Todd, A. Parsons, SPIE Newsroom, 31 June 2001.

[222] Z. Xu, H. Qiang, Y. Chen, and C. Nie, Ceramics Int. 40, 4617 (2014).

[223] M. I. Saidaminov, V. Adinolfi, R. Comin, A. L. Abdelhady, W. Peng, I. Dursun, M. Yuan, S. Hoogland, E. H. Sargent, and O. M. Bakr, Nat. Commun. 6, art. no. 87247 pp (2015).

[224] B. Náfrádi, G. Náfrádi, L. Forró, and E. Horváth, J. Phys. Chem. C 119, 25204 (2015).

[225] S. Yakunin, M. Sytnyk, D. Kriegner, S. Shrestha, M. Richter, G. J. Matt, H. Azimi, C. J. Brabec, J. Stangl, W. V. Kovalenko, and W. Heiss, Nat. Photon. 9, 444 (2015).

[226] Z.-K. Tan, R. S. Moghaddam, M. L. Lai, P. Docampo, R. Higler, F. Deschler, M. Price, A. Sadhanala, L. M. Pazos, D. Credgington, F. Hanusch, T. Bein, H. J. Snaiths, and R. H. Friend, Nat. Nanotechnol. 9, 687 (2014).

[227] G. Xing, N. Mathews, S. S. Lim, N. Yantara, X. Liu, D. Sabba, M. Grätzel, S. Mhaisalkar, and T. C. Sum, Nat. Mater. 13, 476 (2014).

[228] M. Lorenz, M. S. Ramachandra Rao, T. Venkatesan, E. Fortunato, P. Barquinha, R. Branquinho, D. Salgueiro, R. Martins, E. Carlos, A. Liu, F. K. Shan, M. Grundmann, H. Boschker, J. Mukherjee, M. Priyadarshini, N. Das Gupta, D. J. Rogers, F. H. Teherani, E. V. Sandana, P. Bove, K. Rietwyk, A. Zaban, A. Veziridis, A. Weidenkaff, M. Muralidhar, M. Murakami, S. Abel, J. Fompeyrine, J. Zuniga-Perez, R. Ramesh, N. A. Spaldin, S. Ostanin, V. Borisov, I. Mertig, V. Lazenka, G. Srinivasan, W. Prellier, M. Uchida, M. Kawasaki, R. Pentcheva, P. Gegenwart, F. Miletto Granozio, J. Fontcuberta, and N. Pryds, J. Physics D: Applied Physics 49, art. no. 43300153 pp (2016). 